\title{
Milling Stability Prediction with Multiple Delays via the Extended Adams-Moulton-Based Method
}

\author{
Jianfeng Tao, Chengjin Qin, and Chengliang Liu \\ State Key Laboratory of Mechanical System and Vibration, School of Mechanical Engineering, \\ Shanghai Jiao Tong University, Shanghai 200240, China \\ Correspondence should be addressed to Jianfeng Tao; jftao@sjtu.edu.cn
}

Received 16 February 2017; Revised 27 March 2017; Accepted 29 March 2017; Published 7 May 2017

Academic Editor: Oleg V. Gendelman

Copyright (C) 2017 Jianfeng Tao et al. This is an open access article distributed under the Creative Commons Attribution License, which permits unrestricted use, distribution, and reproduction in any medium, provided the original work is properly cited.

\begin{abstract}
The occurrence of machining chatter may undermine the workpiece surface quality, accelerate the tool wear, and even result in serious damage to the machine tools. Consequently, it is of great importance to predict and eliminate the presence of such unstable and detrimental vibration. In this paper, we present an extended Adams-Moulton-based method for the stability prediction of milling processes with multiple delays. Taking the nonuniform pitch cutters or the tool runout into account, the regenerative chatter for milling operations can be formulated as delay differential equations with multiple delays. The dynamics model for milling regenerative chatter is rewritten in the state-space form. Dividing the spindle rotation period equally into small time intervals, the delay terms are approximated by Lagrange interpolation polynomials, and the Adams-Moulton method is adopted to construct the Floquet transition matrix. On this basis, the milling stability can be derived from the spectral radius of the transition matrix based on Floquet theory. The calculation efficiency and accuracy of the proposed algorithm are verified through making comparisons with the semidiscretization method (SDM) and the enhanced multistage homotopy perturbation method (EMHPM). The results show that the proposed method has both high computational efficiency and accuracy.
\end{abstract}

\section{Introduction}

In machining operations, chatter vibration is still one of the main constraints to high productivity and part quality. It is a typical kind of self-excited vibration between the cutter and the workpiece and can occur in almost every machining process. The onset of such detrimental instability may result in poor surface roughness, rapid tool wear, and large reduction of tool life. Therefore, many researches on the modelling, prediction, and avoidance of milling chatter have been conducted [1-3]. Theoretically speaking, modecoupling, frictional, thermomechanical, and regenerative mechanisms can induce chatter to occur [4]. With regard to milling operations, the regenerative chatter is considered as the most common unstable situation. The corresponding mathematical model can be described by delay differential equations (DDEs) with time-periodic coefficients $[5,6]$.

To achieve stable milling operations, one effective and significant technique is selecting proper cutting parameters based on the stability lobe diagrams, which can be acquired via the milling stability prediction. Therefore, many approaches have been proposed to approximate the DDEs to derive the milling stability lobe diagrams, such as numerical methods [7-10], analytical methods [11-13], and semianalytical methods [14-40]. Analytical and semianalytical methods have significant advantages over numerical methods on the computation efficiency. Consequently, they are widely used in industrial applications and gained extensive attention from the academic fields. Altintaş and Budak [11, 12] proposed the zero-order approximation method for the stability prediction of milling operations in the frequency domain. The prominent advantage of this approach is its low computational cost. Nevertheless, the zero-order approximation method is not quite competent for low radial immersion conditions. To improve the zero-order approximation method, Merdol and Altintas [13] presented the so-called multifrequency solution through including more numbers of harmonics. With the help of the weighted residual method, Bayly et al. [14] introduced the temporal finite element analysis (TFEA) method to predict milling stability. Butcher et al. [15] 
developed the Chebyshev collocation method for the stability analysis of milling processes. Urbikain and coworkers extended the Chebyshev collocation method for various turning processes, including turning of nonrigid parts [16], turning of rigid parts [17], turning with low rotational speeds [18], and heavy-duty turning processes [19]. Insperger et al. [20-22] presented the well-accepted semidiscretization methods (0st SDM and 1st SDM) based on Floquet theory for periodic delayed systems. The semidiscretization methods can effectively be utilized for predicting stability of different milling processes [6]. Consequently, the SDMs are commonly utilized as benchmarks methods for other timedomain semianalytical methods. To obtain higher accuracy and efficiency, Jiang et al. [23] presented a second-order semidiscretization method by utilizing Newton interpolation polynomials and improved precise time-integration algorithm. Different from the SDMs, Ding et al. [24, 25] developed the full-discretization methods (1st FDM and 2nd FDM) for milling stability prediction, in which the state term, the delay term, and the parameter matrix are approximated by linear interpolations, respectively. Three-order and hyperthird-order FDMs were subsequently investigated by Quo et al. [26] and Ozoegwu et al. [27], respectively. However, these methods lead to an increase in computational time since the structures are more complex. Ding et al. $[28,29]$ presented the numerical integration method (NIM) for milling operations with both constant and variable spindle speeds. Niu and coworkers [30] further developed the variable-step numerical integration method (VNIM) for milling stability prediction with periodic spindle speed variation. Different from SDMs and FDMs, Li et al. [31] developed the complete discretization scheme (CDS) by discretizing all parts of DDE and utilizing Euler's method. Xie [32] presented an improved complete discretization method for more efficient stability prediction of milling processes, in which the coefficient matrixes were approximated by linear interpolation. To improve the accuracy of the CDS, Li et al. [33] developed the Runge-Kuttabased complete discretization method. By approximating the term with time-derivative with a weighted linear sum of the corresponding function values, Ding et al. [34] suggested the so-called differential quadrature method (DQM) for the stability analysis of milling operations. Olvera and coworkers [35] combined homotopy method with simulated annealing algorithm for fast prediction of milling stability lobes. Niu et al. [36] proposed the Runge-Kutta methods (CRKM and GRKM). Ding et al. [37] developed the wavelet-based approach for stability analysis of periodic delay differential systems. Zhang et al. [38] suggested Simpson based method (SBM) for the milling stability prediction. Applying the finite difference method and extrapolation method, Zhang et al. [39] presented the numerical differentiation method for stability analysis of milling processes. More recently, Qin et al. [40] presented the Adams-Moulton-based method (AMM) for the stability prediction of milling processes, which has high efficiency and accuracy compared with the 1st SDM and the SBM.

Nevertheless, the above works were mostly conducted based on the ideal milling operations with regular uniform pitch cutters, in which there exists only single time delay.
Taking the nonuniform pitch cutters or the case tool runout into account, the regenerative chatter models for milling operations are described by delay differential equations with multiple delays. As a consequence, many efforts have been made to extend the above algorithms to the multiple delays case. Altintaş et al. [41] developed an analytical method for stability prediction of milling process with variable pitch cutters, which was well validated by extensive milling experiments. The results of their research demonstrated the significant influence of the pitch angles on the stability domain. With the aid of the analytical method, Budak [42, 43] developed an optimal pitch angles design method for increasing the milling stability. On the basis of cluster treatment of characteristic roots method, Olgac and Sipahi [44] studied the stability boundary of milling process with unequally pitched cutters and presented an optimization procedure for the geometry design of variable pitch cutters. Sims et al. [45] employed the modified SDM, the time-averaged SDM, and the TFEA method to investigate the stability of variable pitch and variable helix milling cutters. Their works showed that under small radial immersions condition the cyclic-fold bifurcations can arise for both nonuniform pitch and variable helix milling tools. Based on the updated semidiscretization method from [21], Wan et al. [46] developed a unified method to predict milling stability with multiple delays arising in variable pitch cutters or cutter runout. Zhang et al. $[47,48]$ developed an improved FDM and a variable-step NIM for the stability prediction of milling operations with multiple delays. Compeán and coworkers [49] developed the enhanced multistage homotopy perturbation method (EMHPM) for milling stability analysis with multiple delays. The so-called spectral element approach was introduced by Khasawneh and Mann [50] for stability analysis of timeperiodic delay equations with multiple delays. Jin et al. [5153] presented an improved SDM to investigate the effect of the tool geometries on the stability trends for variable pitch or variable helix milling. Sims [54] introduced an efficient approach to variable helix tool stability based upon the Laplace transform. Ding and coworkers [55] extended the differential quadrature method for stability analysis of dynamic systems with multiple delays. By combining threeorder FDM and variable interpolation technique, Guo et al. [56] proposed a time-domain semianalytical method for prediction of milling stability lobes with nonuniform helix tools.

In recent years, efficient and accurate milling stability prediction has been a key issue both in academic and industrial fields. However, it is difficult to achieve both high computational accuracy and efficiency simultaneously. Based on our previous work [40], this paper develops an extended Adams-Moulton-based method for the milling stability prediction with multiple delays. The remainder of this paper is organized as follows. After the introduction, Section 2 gives a concise description of the dynamics model for milling operations with multiple delays. The extended Adams-Moulton-based method (EAMM) is proposed in Section 3. Section 4 validates the computation accuracy and efficiency of the proposed method by a two-DOF milling operation. Finally, the conclusion is drawn in Section 5. 


\section{Mathematical Model of Milling Operations}

Theoretically speaking, when the constant pitch cutter is employed and the cutter runout is neglected, there exists only one delay term in the system dynamics equation. Based on $[1$, $6,21]$, the dynamics model of milling operations that include the regenerative effect can be modelled by the following delay differential equation:

$$
\mathbf{M q} \ddot{\mathbf{(}}(t)+\mathbf{C q} \dot{(} t)+\mathbf{K q}(t)=a_{p} \mathbf{K}_{c}(t)[\mathbf{q}(t)-\mathbf{q}(t-T)],
$$

where $\mathbf{q}(t)$ denotes the modal vector of the cutter. $\mathbf{M}, \mathbf{C}$, and $\mathbf{K}$ represent the modal parameter matrixes. $a_{p}$ denotes the depth of cut. $\mathbf{K}_{c}(t)$ is the periodic coefficient matrix, that is, $\mathbf{K}_{c}(t)=\mathbf{K}_{c}(t+T)$. $T$ is the time delay. For milling operations, $T$ equals the tooth passing period.

However, the actual milling cutters cannot be always completely symmetrical. Therefore, there may exist a certain deviation between the spindle rotation axis and the tool geometry axis, which constitutes the so-called cutter runout. In addition, when the variable pitch cutter without cutter runout is considered, any cutting point will always remove the surface left by the first previous tooth. In this case, due to the unevenly pitched space angle, the delays that equal relevant tooth passing period will be different. Consequently, in regard to the practical milling process, the governing dynamics equation should be modelled as delay differential equations with multiple delays instead. Based on [41, 46, 47], the governing equation of the milling process with multiple delays can be modelled by

$$
\begin{aligned}
\mathbf{M q} \ddot{\mathbf{(}}(t)+\mathbf{C q} \dot{(} t)+\mathbf{K q}(t) \\
=\sum_{j=1}^{N} \mathbf{K}_{j}(t)\left[\mathbf{q}(t)-\mathbf{q}\left(t-T_{j}\right)\right],
\end{aligned}
$$

where $N$ denotes the number of flutes, and the periodic coefficient matrix $\mathbf{K}_{j}(t)$ is defined as

$$
\mathbf{K}_{j}(t)=\left(\begin{array}{ll}
h_{j x x}(t) & h_{j x y}(t) \\
h_{j y x}(t) & h_{j y y}(t)
\end{array}\right)
$$

Without loss of generality, we utilize milling with nonconstant pitch cutter to illustrate the mathematical model of milling with multiple delays. Based on [41, 46, 47], the tool is firstly divided into a finite number of disk elements along the axial direction. Then the resultant cutting forces in the $X$ and $Y$ directions are acquired by numerically summing the force components acting on each individual element. In such conditions, $h_{j x x}(t), h_{j x y}(t), h_{j y x}(t)$, and $h_{j y y}(t)$ can be finally obtained by

$$
\begin{gathered}
h_{j x x}(t)=\int_{0}^{a_{p}}-\left[K_{t} \cos \left(\phi_{j}(t, z)\right)+K_{n} \sin \left(\phi_{j}(t, z)\right)\right] \\
\cdot g\left(\phi_{j}(t, z)\right) \sin \left(\phi_{j}(t, z)\right) d z,
\end{gathered}
$$

$$
\begin{aligned}
& h_{j x y}(t)=\int_{0}^{a_{p}}-\left[K_{t} \cos \left(\phi_{j}(t, z)\right)+K_{n} \sin \left(\phi_{j}(t, z)\right)\right] \\
& \cdot g\left(\phi_{j}(t, z)\right) \cos \left(\phi_{j}(t, z)\right) d z, \\
& h_{j y x}(t) \\
& \quad=\int_{0}^{a_{p}}-\left[-K_{t} \sin \left(\phi_{j}(t, z)\right)+K_{n} \cos \left(\phi_{j}(t, z)\right)\right] \\
& \quad \cdot g\left(\phi_{j}(t, z)\right) \sin \left(\phi_{j}(t, z)\right) d z, \\
& h_{j y y}(t) \\
& \quad=\int_{0}^{a_{p}}-\left[-K_{t} \sin \left(\phi_{j}(t, z)\right)+K_{n} \cos \left(\phi_{j}(t, z)\right)\right] \\
& \quad \cdot g\left(\phi_{j}(t, z)\right) \cos \left(\phi_{j}(t, z)\right) d z,
\end{aligned}
$$

where $K_{t}$ and $K_{n}$ are the tangential and normal cutting force coefficients, respectively. $\phi_{j}(t, z)$ denotes the angular position of the $j$ th tooth, given by

$$
\phi_{j}(t, z)= \begin{cases}\frac{2 \pi \Omega}{60} t-\frac{z \tan \beta}{R}, & j=1, \\ \frac{2 \pi \Omega}{60} t-\frac{z \tan \beta}{R}+\sum_{j=2}^{j} \psi_{j}, & 1<j<N,\end{cases}
$$

where $\beta$ denotes the helix angle, $\psi_{j}$ represents the pitch angle between the $j$ th tooth and the $(j-1)$ th tooth, $R$ is the radius of the cutter, and $\Omega$ represents the spindle speed.

The screen function $g\left(\phi_{j}(t)\right)$ is utilized to determine whether the tool is cutting the part, given by

$$
g\left(\phi_{j}(t, z)\right)= \begin{cases}1, & \phi_{\mathrm{st}}<\bmod \left(\phi_{j}(t), 2 \pi\right)<\phi_{\mathrm{ex}} \\ 0, & \text { otherwise }\end{cases}
$$

where $\phi_{\text {st }}$ and $\phi_{\text {ex }}$ represent the start and exit angles of tool. For downmilling, $\phi_{\text {st }}=\operatorname{arcos}(2 a / D-1)$, and $\phi_{\text {ex }}=\pi$; for upmilling, $\phi_{\mathrm{st}}=0$, and $\phi_{\mathrm{ex}}=\operatorname{arcos}(1-2 a / D)$, where $a / D$ is the radial immersion ratio.

For more details of the milling dynamics models, one can refer to $[1,6,21,41,46,47]$.

\section{Extended Adams-Moulton-Based Method}

To numerically determine the milling stability, the governing equation (2) should be reexpressed in the state-space form. Specifically, define $\mathbf{p}(t)=\mathbf{M q}(t)+\mathbf{C q}(t) / 2$ and $\mathbf{y}(t)=$ $[\mathbf{q}(t), \mathbf{p}(t)]^{T} ;(2)$ can be rewritten as

$$
\dot{\mathbf{y}(t)}=\mathbf{A}_{c} \mathbf{y}(t)+\sum_{j=1}^{N} \mathbf{A}_{j}(t)\left[\mathbf{y}(t)-\mathbf{y}\left(t-T_{j}\right)\right],
$$


where

$$
\begin{aligned}
\mathbf{A}_{c} & =\left(\begin{array}{cc}
-\frac{\mathbf{M}^{-1} \mathbf{C}}{2} & \mathbf{M}^{-1} \\
\frac{\mathbf{C M}^{-1} \mathbf{C}}{4}-\mathbf{K} & -\frac{\mathbf{C M}^{-1}}{2}
\end{array}\right), \\
\mathbf{A}_{j}(t) & =\left(\begin{array}{cr}
\mathbf{0} & \mathbf{0} \\
\mathbf{K}_{j}(t) & \mathbf{0}
\end{array}\right) .
\end{aligned}
$$

By applying the state-space theory, the analytical response of (10) can be deduced as

$$
\begin{aligned}
\mathbf{y}(t)= & e^{\mathbf{A}_{c}\left(t-t_{0}\right)} \mathbf{y}\left(t_{0}\right) \\
& +\sum_{j=1}^{N} \int_{t_{0}}^{t} e^{\mathbf{A}_{c}(t-\varepsilon)} \mathbf{A}_{j}(\varepsilon)\left[\mathbf{y}(\varepsilon)-\mathbf{y}\left(\varepsilon-T_{j}\right)\right] d \varepsilon,
\end{aligned}
$$

where $\mathbf{y}\left(t_{0}\right)$ denotes initial state point and $t_{0}$ represents the initial time instant.

Firstly, the spindle rotation period $T$ is divided equally into $m$ small time intervals, which makes $T=m h$. Obviously, these $(m+1)$ discretized points can be expressed as

$$
t_{n}=t_{0}+(n-1) h, \quad n=1,2, \ldots, m+1 .
$$

During the $n$th time interval, that is, $t_{n}<t<t_{n+1}$, (12) can be equivalently reexpressed as

$$
\begin{aligned}
\mathbf{y}(t)= & e^{\mathbf{A}_{c}\left(t-t_{n}\right)} \mathbf{y}\left(t_{n}\right) \\
& +\sum_{j=1}^{N} \int_{t_{n}}^{t} e^{\mathbf{A}_{c}(t-\varepsilon)} \mathbf{A}_{j}(\varepsilon)\left[\mathbf{y}(\varepsilon)-\mathbf{y}\left(\varepsilon-T_{j}\right)\right] d \varepsilon .
\end{aligned}
$$

By substituting $t=t_{n+1}, \mathbf{y}\left(t_{n+1}\right)$ is defined as

$$
\begin{aligned}
& \mathbf{y}\left(t_{n+1}\right) \\
& =e^{\mathbf{A}_{c} h} \mathbf{y}\left(t_{n}\right) \\
& \quad+\sum_{j=1}^{N} \int_{t_{n}}^{t_{n+1}} e^{\mathbf{A}_{c}\left(t_{n+1}-\varepsilon\right)} \mathbf{A}_{j}(\varepsilon)\left[\mathbf{y}(\varepsilon)-\mathbf{y}\left(\varepsilon-T_{j}\right)\right] d \varepsilon .
\end{aligned}
$$

In order to simplify the derivation process, we will use some abbreviated expressions; that is, $\mathbf{y}_{n}$ denotes $\mathbf{y}\left(t_{n}\right), \mathbf{y}_{n-T}$ denotes $\mathbf{y}\left(t_{n}-T\right)$, and $\mathbf{A}_{n}$ denotes $\mathbf{A}\left(t_{n}\right)$. It is noted that (15) is derived from the analytical solution. Consequently, the key to solving (15) is to approximate the Duhamel term with high accuracy and numerical stability. Based on the two-step Adams-Moulton method, the state term $\mathbf{y}_{n+1}$ can be approximated by

$$
\begin{aligned}
\mathbf{y}_{n+1} & =e^{\mathbf{A}_{c} h} \mathbf{y}_{n}+\sum_{j=1}^{N} \frac{h}{12}\left(5 \mathbf{A}_{j, n+1}\left[\mathbf{y}_{n+1}-\mathbf{y}_{n+1-T_{j}}\right]\right. \\
& +8 e^{\mathbf{A}_{c} h} \mathbf{A}_{j, n}\left[\mathbf{y}_{n}-\mathbf{y}_{n-T_{j}}\right] \\
& \left.-e^{2 h \mathbf{A}_{c}} \mathbf{A}_{j, n-1}\left[\mathbf{y}_{n-1}-\mathbf{y}_{n-1-T_{j}}\right]\right) .
\end{aligned}
$$

When the time delay $T_{j}$ is not equal to integer multiples of the step length $h$, the delay term $\mathbf{y}_{n-T_{j}}$ should be interpolated by using the relevant boundary values. Define $m_{j}=\operatorname{fix}\left(T_{j} / h\right)$; then $T_{j}=m_{j} h+\eta_{j}, \eta_{j}=T_{j}-m_{j} h$, where the function fix $(s)$ denotes the integer part of $s$. For example, we can approximate $\mathbf{y}_{n+1-T_{j}}$ linearly by using the two boundary values, that is, $\mathbf{y}_{n+1-m_{j}}$ and $\mathbf{y}_{n-m_{j}}$, resulting in

$$
\begin{aligned}
\mathbf{y}_{n+1-T_{j}} & =\mathbf{y}_{n+1-m_{j}-\eta_{j}} \\
& =\frac{\eta_{j}}{h} \mathbf{y}_{n-m_{j}+m-T}+\frac{h-\eta_{j}}{h} \mathbf{y}_{n+1-m_{j}+m-T} .
\end{aligned}
$$

Similarly, the delay terms $\mathbf{y}_{n-T_{j}}$ and $\mathbf{y}_{n-1-T_{j}}$ can be approximated linearly by

$$
\begin{aligned}
\mathbf{y}_{n-T_{j}} & =\frac{\eta_{j}}{h} \mathbf{y}_{n-1-m_{j}+m-T}+\frac{h-\eta_{j}}{h} \mathbf{y}_{n-m_{j}+m-T}, \\
\mathbf{y}_{n-1-T_{j}} & =\frac{\eta_{j}}{h} \mathbf{y}_{n-2-m_{j}+m-T}+\frac{h-\eta_{j}}{h} \mathbf{y}_{n-1-m_{j}+m-T} .
\end{aligned}
$$

By substituting (17)-(19) into (16), one can read

$$
\begin{aligned}
\mathbf{P}_{n-1} \mathbf{y}_{n-1}+\mathbf{P}_{n} \mathbf{y}_{n}+\mathbf{P}_{n+1} \mathbf{y}_{n+1} \\
=\sum_{j=1}^{N} \mathbf{Q}_{n-2+m-m_{j}}^{j} \mathbf{y}_{n-2-m_{j}+m-T} \\
\quad+\sum_{j=1}^{N} \mathbf{Q}_{n-1+m-m_{j}}^{j} \mathbf{y}_{n-1-m_{j}+m-T} \\
\quad+\sum_{j=1}^{N} \mathbf{Q}_{n+m-m_{j}}^{j} \mathbf{y}_{n-m_{j}+m-T} \\
+\sum_{j=1}^{N} \mathbf{Q}_{n+1+m-m_{j}}^{j} \mathbf{y}_{n+1-m_{j}+m-T},
\end{aligned}
$$

where

$$
\begin{aligned}
\mathbf{P}_{n-1} & =\sum_{j=1}^{N} \frac{h}{12} e^{2 h \mathbf{A}_{c}} \mathbf{A}_{j, n-1}, \\
\mathbf{P}_{n} & =-e^{\mathbf{A}_{c} h}-\sum_{j=1}^{N} \frac{2 h}{3} e^{\mathbf{A}_{c} h} \mathbf{A}_{j, n}, \\
\mathbf{P}_{n+1} & =\mathbf{I}-\sum_{j=1}^{N} \frac{5 h}{12} \mathbf{A}_{j, n+1}, \\
\mathbf{Q}_{n-2+m-m_{j}}^{j} & =\frac{\eta_{j}}{12} e^{2 h \mathbf{A}_{c}} \mathbf{A}_{j, n-1}, \\
\mathbf{Q}_{n-1+m-m_{j}}^{j} & =\frac{h-\eta_{j}}{12} e^{2 h \mathbf{A}_{c}} \mathbf{A}_{j, n-1}-\frac{2 \eta_{j}}{3} e^{\mathbf{A}_{c} h} \mathbf{A}_{j, n}, \\
\mathbf{Q}_{n+m-m_{j}}^{j} & =-\frac{2 h-2 \eta_{j}}{3} e^{\mathbf{A}_{c} h} \mathbf{A}_{j, n}-\frac{5 \eta_{j}}{12} \mathbf{A}_{j, n+1}, \\
\mathbf{Q}_{n+1+m-m_{j}}^{j} & =-\frac{5 h-5 \eta_{j}}{12} \mathbf{A}_{j, n+1} .
\end{aligned}
$$


In addition, $\mathbf{y}_{2}$ can be approximated with the one-step Adams-Moulton formula

$$
\begin{gathered}
\left(-e^{\mathbf{A}_{c} h}-\sum_{j=1}^{N} \frac{h}{2} e^{\mathbf{A}_{c} h} \mathbf{A}_{j, 1}\right) \mathbf{y}_{1}+\left(\mathbf{I}-\sum_{j=1}^{N} \frac{h}{2} \mathbf{A}_{j, 2}\right) \mathbf{y}_{2} \\
=-\sum_{j=1}^{N} \frac{h}{2} e^{\mathbf{A}_{c} h} \mathbf{A}_{j, 1} \mathbf{y}_{1-T_{j}}-\sum_{j=1}^{N} \frac{h}{2} \mathbf{A}_{j, 2} \mathbf{y}_{2-T_{j}} .
\end{gathered}
$$

Let $n=1$ and substituting (17) and (18) into (22) yields

$$
\begin{aligned}
\mathbf{E y}_{1}+\mathbf{F y}_{2}= & \sum_{j=1}^{N} \mathbf{U}_{0+m-m_{j}}^{j} \mathbf{y}_{0-m_{j}+m-T} \\
& +\sum_{j=1}^{N} \mathbf{V}_{1+m-m_{j}}^{j} \mathbf{y}_{1-m_{j}+m-T} \\
& +\sum_{j=1}^{N} \mathbf{W}_{2+m-m_{j}}^{j} \mathbf{y}_{2-m_{j}+m-T},
\end{aligned}
$$

where

$$
\begin{aligned}
\mathbf{E} & =-e^{\mathbf{A}_{c} h}-\sum_{j=1}^{N} \frac{h}{2} e^{\mathbf{A}_{c} h} \mathbf{A}_{j, 1}, \\
\mathbf{F} & =\mathbf{I}-\sum_{j=1}^{N} \frac{h}{2} \mathbf{A}_{j, 2}, \\
\mathbf{U}_{0+m-m_{j}}^{j} & =-\frac{\eta_{j}}{2} e^{\mathbf{A}_{c} h} \mathbf{A}_{j, 1},
\end{aligned}
$$

$$
\begin{aligned}
\mathbf{V}_{1+m-m_{j}}^{j} & =-\frac{h-\eta_{j}}{2} e^{\mathbf{A}_{c} h} \mathbf{A}_{j, 1}-\frac{\eta_{j}}{2} \mathbf{A}_{j, 2}, \\
\mathbf{W}_{2+m-m_{j}}^{j} & =-\frac{h-\eta_{j}}{2} \mathbf{A}_{j, 2} .
\end{aligned}
$$

Obviously, $\mathbf{y}_{1}$ and $\mathbf{y}_{m+1-T}$ satisfy

$$
\mathbf{y}_{1}=\mathbf{y}_{m+1-T}
$$

By combining (20), (23), and (25), a discrete map can be obtained by
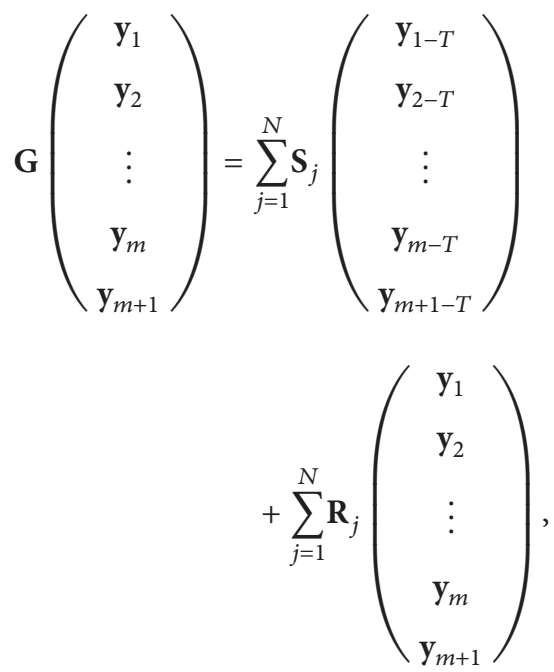

where

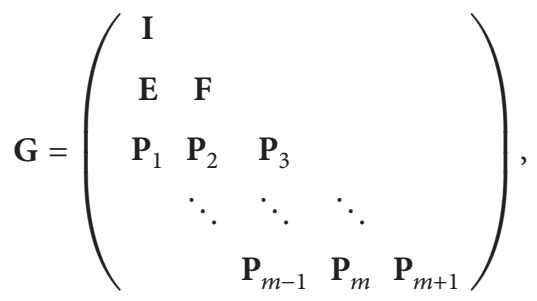

$$
\begin{aligned}
& \mathbf{S}_{j}=\left(\begin{array}{ccccccc} 
& & & & & & \frac{\mathbf{I}}{N} \\
\mathbf{U}_{0+m-m_{j}}^{j} & \mathbf{V}_{1+m-m_{j}}^{j} & \mathbf{W}_{2+m-m_{j}}^{j} & & & & \\
\mathbf{Q}_{0+m-m_{j}}^{j} & \mathbf{Q}_{1+m-m_{j}}^{j} & \mathbf{Q}_{2+m-m_{j}}^{j} & \mathbf{Q}_{3+m-m_{j}}^{j} & & & \\
& \mathbf{Q}_{1+m-m_{j}}^{j} & \mathbf{Q}_{2+m-m_{j}}^{j} & \mathbf{Q}_{3+m-m_{j}}^{j} & \mathbf{Q}_{4+m-m_{j}}^{j} & & \\
& & \ddots & \ddots & \ddots & \ddots & \\
& & & \mathbf{Q}_{m-2}^{j} & \mathbf{Q}_{m-1}^{j} & \mathbf{Q}_{m}^{j} & \mathbf{Q}_{m+1}^{j} \\
& & & & \mathbf{Q}_{m-1}^{j} & \mathbf{Q}_{m}^{j} & \mathbf{Q}_{m+1}^{j} \\
& & & & & \mathbf{Q}_{m}^{j} & \mathbf{Q}_{m+1}^{j} \\
& & & & & & \mathbf{Q}_{m+1}^{j}
\end{array}\right),
\end{aligned}
$$




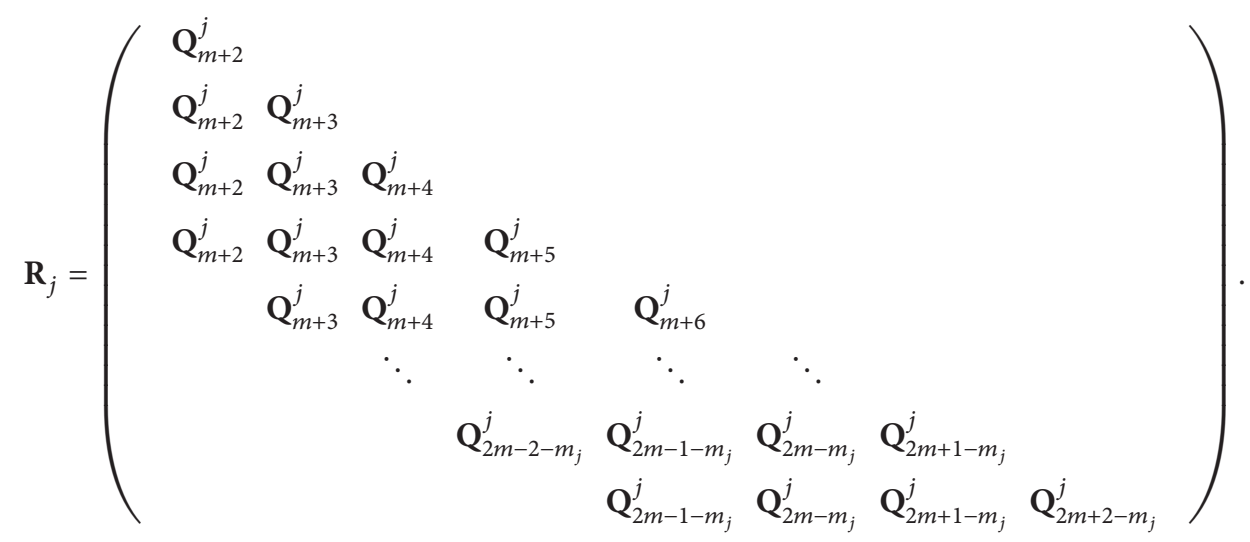

Finally, the transition matrix $\Psi$ with the EAMM can be written as

$$
\boldsymbol{\Psi}=\left(\mathbf{G}-\sum_{j=1}^{N} \mathbf{R}_{j}\right)^{-1}\left(\sum_{j=1}^{N} \mathbf{S}_{j}\right)
$$

According to Floquet theory, the stability of periodic systems depends on the spectral radius of the transition matrix. Consequently, the stability of milling operations can be obtained from the following criterion:

$$
\rho(\Psi) \begin{cases}>1, & \text { unstable } \\ =1, & \text { critical } \\ <1, & \text { stable }\end{cases}
$$

where $\rho(\Psi)$ presents the spectral radius; that is, $\rho(\Psi)=$ $\max (|\lambda(\Psi)|)$.

It should be noted that the construction of the Floquet transition matrix should be based on the period of the coefficient matrix rather than on that of the delay terms. For milling processes with single delay, the time period $T$ is equal to the tooth passing period. However, it is equal to the spindle speed period for milling processes with multiple delays. Consequently, the spindle speed period is discretized. On the other hand, the ratio of time period to time delay (ROTPTD) is equal to one for milling processes with single delay, while it can be arbitrary for milling with multiple delays. In the proposed method, the delay terms are approximated by Lagrange interpolation polynomials with corresponding boundary values. Consequently, the proposed algorithm can be utilized for stability analysis of periodic delay systems with an arbitrary ROTPTD.

\section{Validation and Comparison}

In this section, the computation efficiency and accuracy of the proposed method are verified by a two-DOF milling operation with variable pitch cutter in [41]. Note that Wan et al. [46] had extended the semidiscretization method in [21] to the milling stability analysis with multiple delays. To evaluate the effectiveness of the proposed method, we will make comparisons with the semidiscretization method (SDM) and the enhanced multistage homotopy perturbation method (EMHPM), in which the same program structure and the same model parameters are adopted.

Based on [41], the dynamics model of two-DOF milling operations can be modelled as

$$
\begin{aligned}
& \left(\begin{array}{cc}
m_{t x} & 0 \\
0 & m_{t y}
\end{array}\right)\left(\begin{array}{c}
x \ddot{(} t) \\
y \ddot{(} t)
\end{array}\right) \\
& +\left(\begin{array}{cc}
2 \zeta_{x} \omega_{n x} m_{t x} & 0 \\
0 & 2 \zeta \omega_{n y} m_{t y}
\end{array}\right)\left(\begin{array}{c}
x \dot{(}(t) \\
y \dot{(t}(t)
\end{array}\right) \\
& +\left(\begin{array}{cc}
\omega_{n x}{ }^{2} m_{t x} & 0 \\
0 & \omega_{n y}{ }^{2} m_{t y}
\end{array}\right)\left(\begin{array}{l}
x(t) \\
y(t)
\end{array}\right) \\
& =\sum_{j=1}^{N}\left(\begin{array}{ll}
h_{j x x}(t) & h_{j x y}(t) \\
h_{j y x}(t) & h_{j y y}(t)
\end{array}\right)\left[\left(\begin{array}{l}
x(t) \\
y(t)
\end{array}\right)\right. \\
& \left.-\left(\begin{array}{c}
x\left(t-T_{j}\right) \\
y\left(t-T_{j}\right)
\end{array}\right)\right] \text {. }
\end{aligned}
$$

In (30), $m_{t x}, m_{t y}, \omega_{n x}, \omega_{n y}, \zeta_{x}$, and $\zeta_{y}$ represent the modal parameters of the system. The nonconstant pitch cutter has four flutes, a diameter of $19.05 \mathrm{~mm}$, and a helix angle of $30^{\circ}$. There are three modes in the $X$ direction and one mode in the $Y$ direction. In-depth analysis showed that the second mode in the $X$ direction has dominant influence on the system stability. Consequently, the other two modes in the $X$ direction are not taken into consideration. The modal parameters of the downmilling system are the same as [41]: the modal masses are $m_{t x}=1.4986 \mathrm{~kg}$ and $m_{t y}=1.199 \mathrm{~kg}$, the natural angular frequencies are $\omega_{n x}=563.6 \times 2 \pi \mathrm{rad} / \mathrm{s}$ 
and $\omega_{n y}=516.21 \times 2 \pi \mathrm{rad} / \mathrm{s}$, and the damping ratios are $\zeta_{x}=0.0558$ and $\zeta_{y}=0.025$. The coefficient matrix $\mathbf{K}_{c}(t)$ is the same as that given by (4). The time delay $T_{j}$ represents the pitch period related to the pitch angle. The pitch angles of the cutter are $70^{\circ}-110^{\circ}-70^{\circ}-110^{\circ}$, which results in four time delays; that is, $T_{1}=T_{3}=7 / 36 T$, and $T_{2}=T_{4}=11 / 36 T$. The part material is Al356 alloy, and the cutting force coefficients are $K_{t}=6.79 \times 10^{8} \mathrm{~N} / \mathrm{m}^{2}$ and $K_{n}=2.56 \times 10^{8} \mathrm{~N} / \mathrm{m}^{2}$.
With the same matrix transformation presented in Section 2, (30) can be rewritten in the state-space form:

$$
\dot{\mathbf{y}}(t)=\mathbf{A}_{c} \mathbf{y}(t)+\sum_{j=1}^{N} \mathbf{A}_{j}(t)\left[\mathbf{y}(t)-\mathbf{y}\left(t-T_{j}\right)\right],
$$

where

$$
\begin{aligned}
& \mathbf{A}_{c}=\left(\begin{array}{cccc}
-\zeta \omega_{n x} & 0 & \frac{1}{m_{t x}} & 0 \\
0 & -\zeta \omega_{n y} & 0 & \frac{1}{m_{t y}} \\
\left(\zeta_{x}{ }^{2}-1\right) \omega_{n x}{ }^{2} m_{t x} & 0 & -\zeta_{x} \omega_{n x} & 0 \\
0 & \left(\zeta_{y}{ }^{2}-1\right) \omega_{n y}{ }^{2} m_{t y} & 0 & -\zeta_{y} \omega_{n y}
\end{array}\right), \\
& \mathbf{A}_{j}(t)=\left(\begin{array}{cccc}
0 & 0 & 0 & 0 \\
0 & 0 & 0 & 0 \\
h_{j x x}(t) & h_{j x y}(t) & 0 & 0 \\
h_{j y x}(t) & h_{j y y}(t) & 0 & 0
\end{array}\right) .
\end{aligned}
$$

To verify the feasibility of the proposed method, both large and low radial immersion milling conditions need to be investigated. First, the radial immersion ratio $a / D$ is set as 1 and 0.6 to examine large radial immersions conditions. The stability lobe diagrams are constructed over a $200 \times$ 120 sized grid. The time interval $m$ is selected as 55 and 75 , respectively. The cutting parameter combinations are set as follows: the spindle speed $\Omega$ ranges from $2 \mathrm{krpm}$ to $12 \mathrm{krpm}$, and the depths of cut $a_{p}$ ranges from 0 to $15 \mathrm{~mm}$. The reference stability limits demoded by the red line are computed by the SDM with $m=600$. Figures 1 and 2 show the stability lobe diagrams under large radial immersion conditions and the efficiency of these methods. The results demonstrate that the proposed method achieves a much higher computational efficiency than the SDM and the EMHPM. Indeed, the computation time of the proposed method can be reduced by $67-70 \%$ and $45-52 \%$, compared with those of the SDM and the EMHPM, respectively. The stability lobe diagrams computed by the proposed method agree well with the exact stability lobe diagrams. In general, the accuracy of the stability lobe diagrams with the EAMM is higher than those with the other two methods based on the same computational parameters. The relative errors of these methods over the spindle speed range from $2000 \mathrm{rpm}$ to $5000 \mathrm{rpm}$ are presented in Figure 3. It demonstrates that the EAMM is of the highest accuracy. For instance, when compared with the SDM, the accuracy can be improved by up to $23 \%$ at the spindle speed $\Omega=2000 \mathrm{rpm}$ with the radial immersion ratio $a / D=1$ and by up to $38 \%$ with the radial immersion ratio $a / D=0.6$.
Meanwhile, we set the radial immersion ratio $a / D$ set as 0.3 and 0.1 to examine low radial immersions milling. The time interval $m$ is also selected as 55 and 75 . The stability lobe diagrams are constructed over a $200 \times 120$ sized grid. The range of the spindle speed $\Omega$ remains the same as the previous case, while the depths of cut $a_{p}$ range from 0 to $20 \mathrm{~mm}$. The exact stability limits demoded by the red line are also calculated by the SDM with $m=600$. Figures 4 and 5 show the stability lobe diagrams under low radial immersion conditions and the computational time of the SDM, the EMHPM, and the EAMM. It shows that the stability charts computed by the proposed method also agree well with the reference stability lobe diagrams for low radial immersions conditions. Moreover, the proposed method achieves a much higher computational efficiency than the other two methods. Compared with the SDM and the EMHPM, the computation time of the proposed method can be reduced by $67-69 \%$ and $45-53 \%$, respectively. In addition, the results show that under the same computational parameters the accuracy of the EAMM is better than the SDM and the EMHPM. The relative errors of these three methods over the spindle speed range from $2000 \mathrm{rpm}$ to $5500 \mathrm{rpm}$ are presented in Figure 6. It shows that the accuracy of the EAMM is much better than the other two methods over this range of spindle speeds. For instance, when compared with the SDM, the accuracy can be improved by up to $22 \%$ at the spindle speed $\Omega=2000 \mathrm{rpm}$ and the radial immersion ratio $a / D=0.3$ and by up to $19 \%$ at the spindle speed $\Omega=3200 \mathrm{rpm}$ and the radial immersion ratio $a / D=0.1$. 


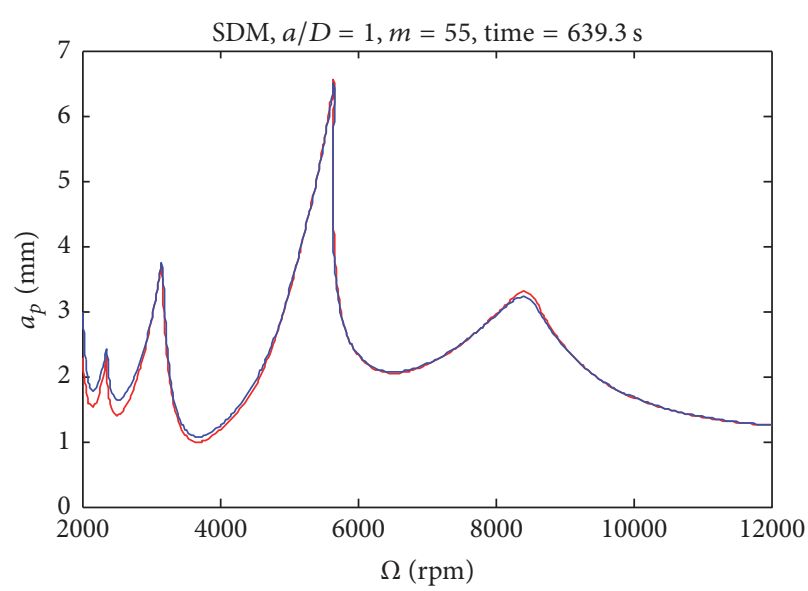

- Reference

- SDM

(a)

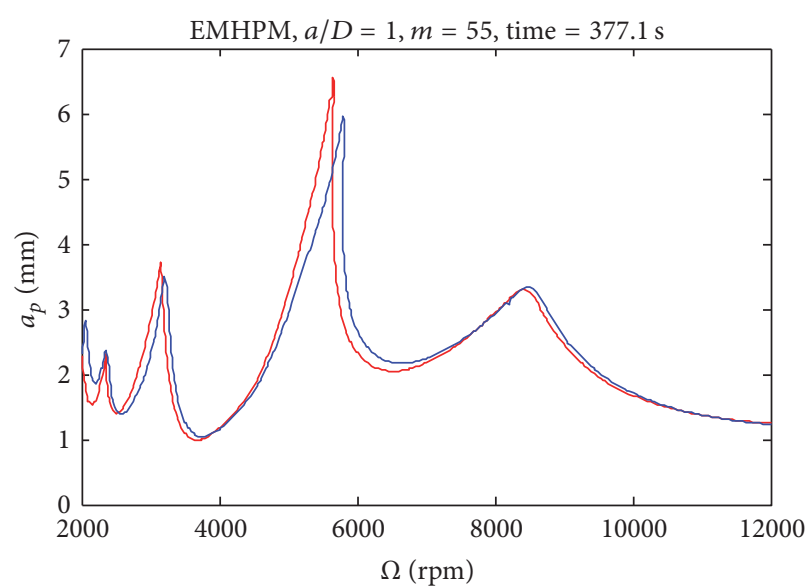

- Reference

— EMHPM

(c)

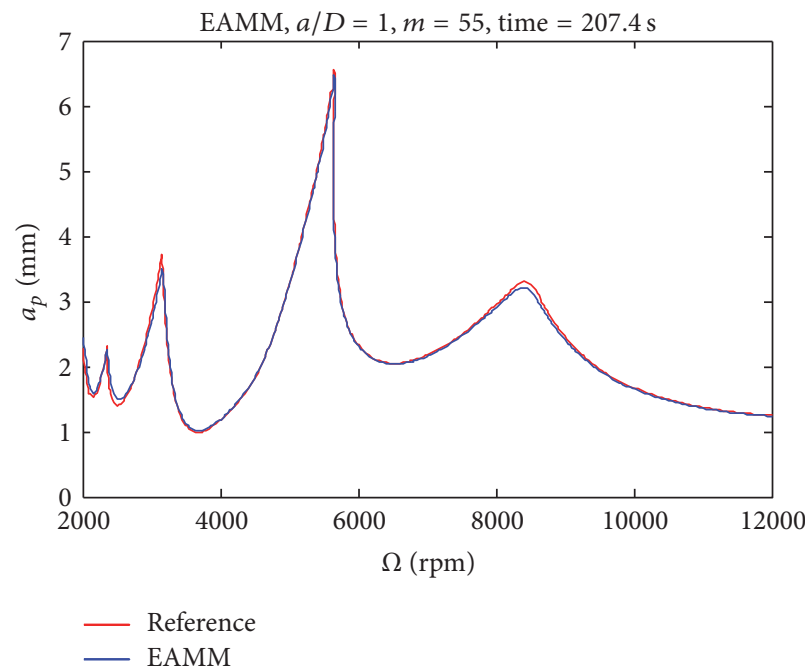

(e)

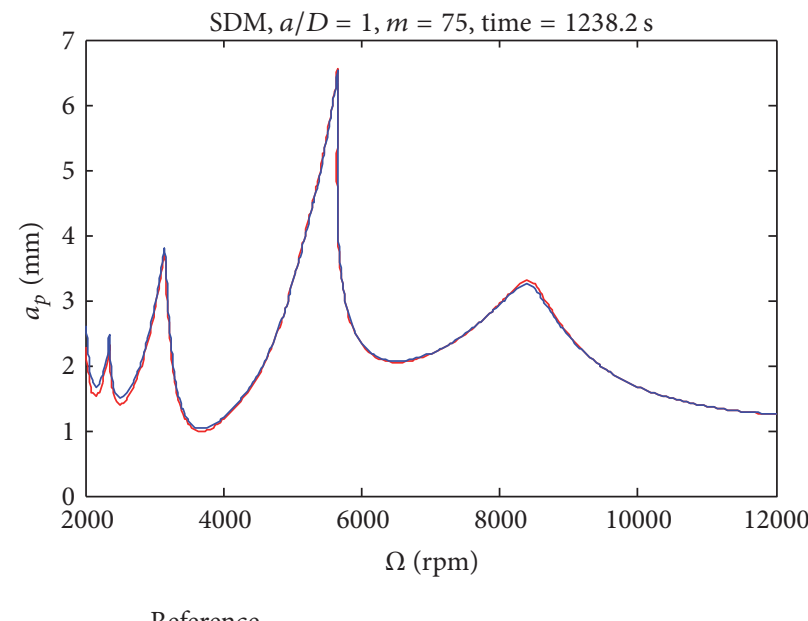

(b)

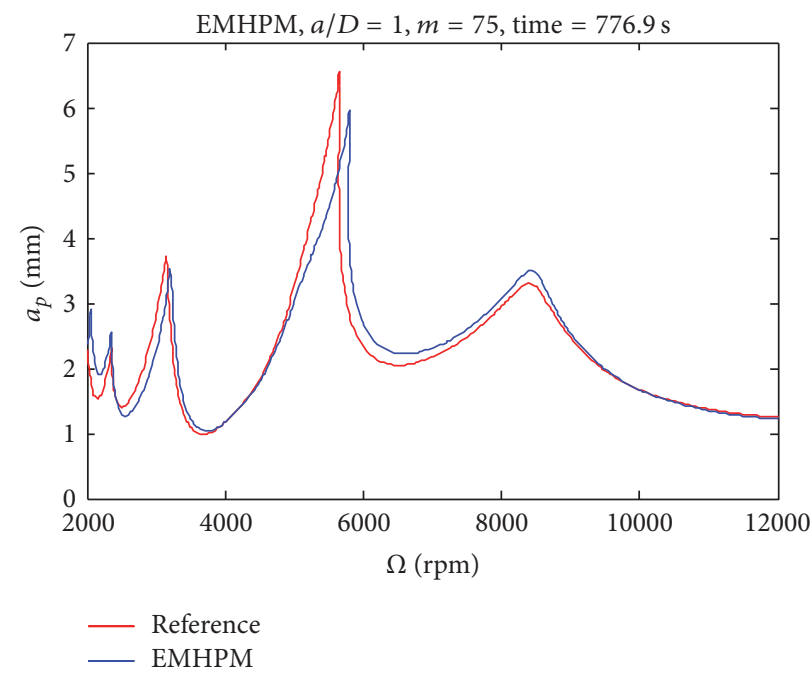

(d)

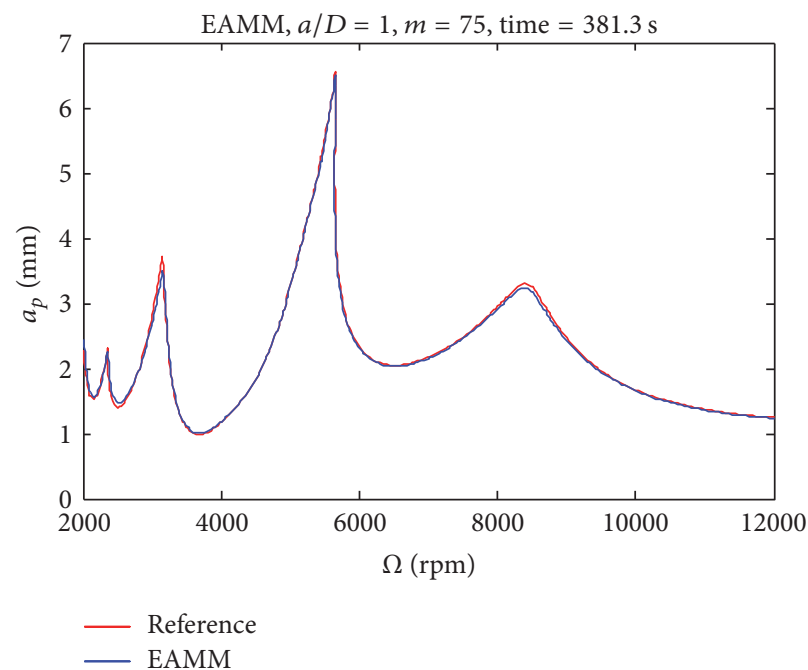

(f)

FIGURE 1: Stability lobe diagrams computed by the SDM, the EMHPM, and the EAMM with the radial immersion ratio $a / D=1$. 

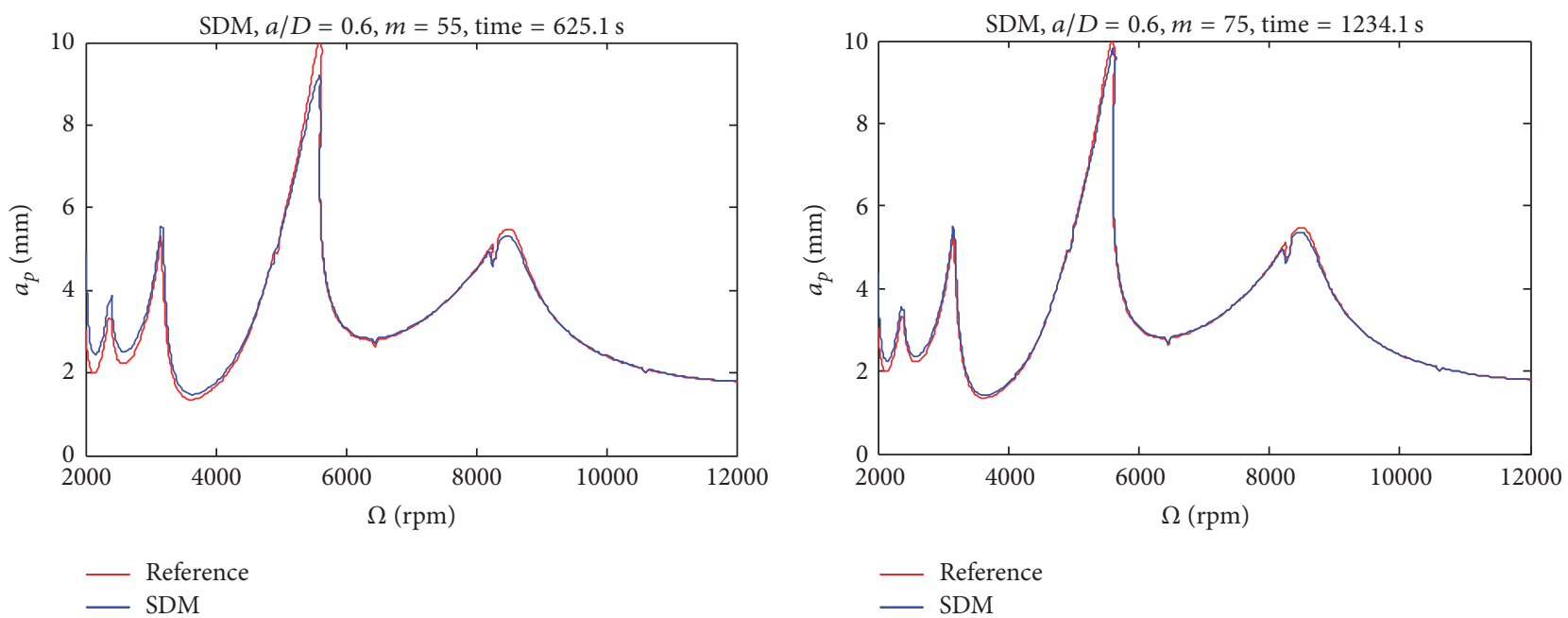

(a)
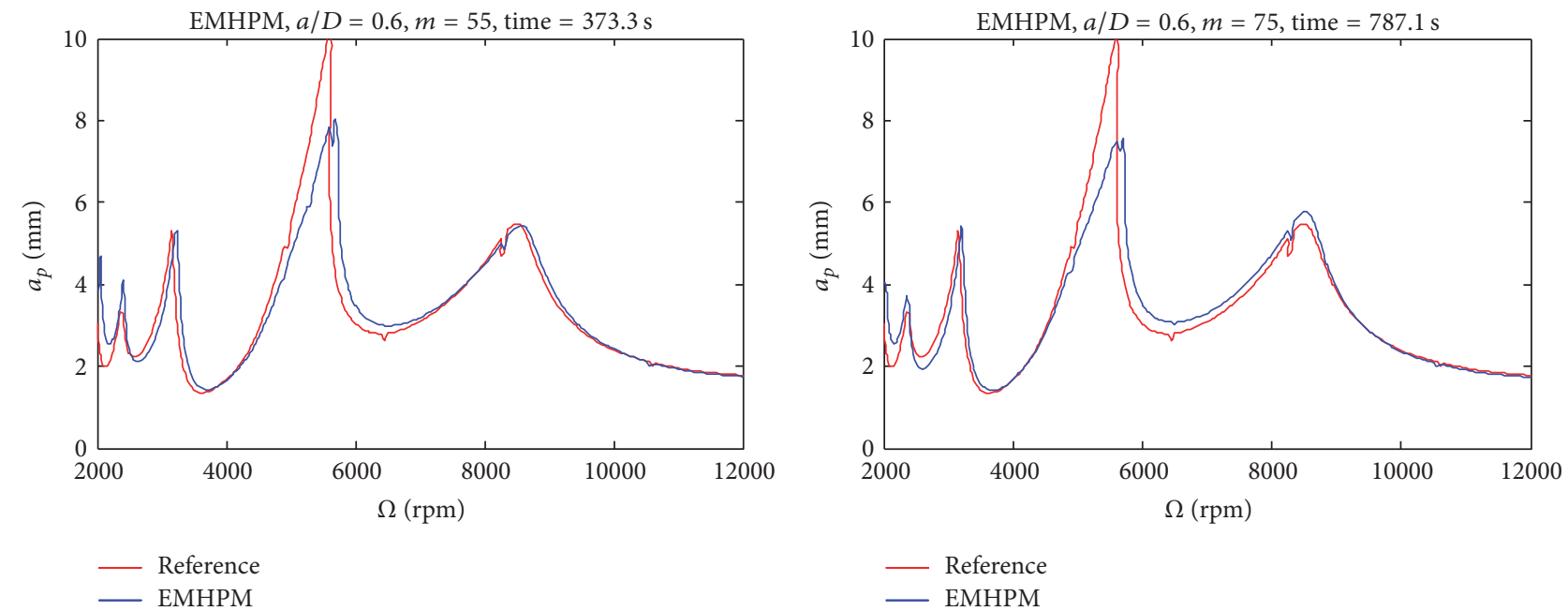

(c)

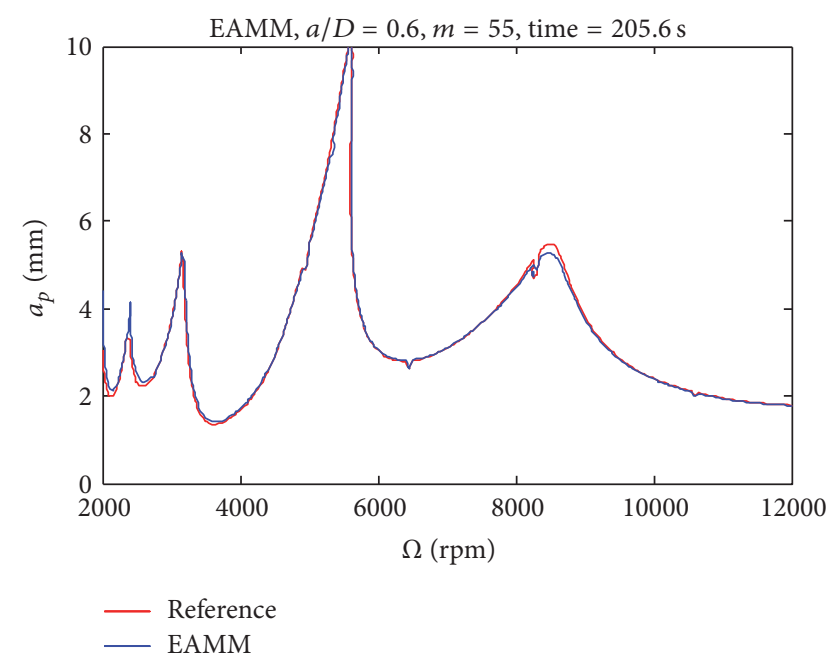

(e)

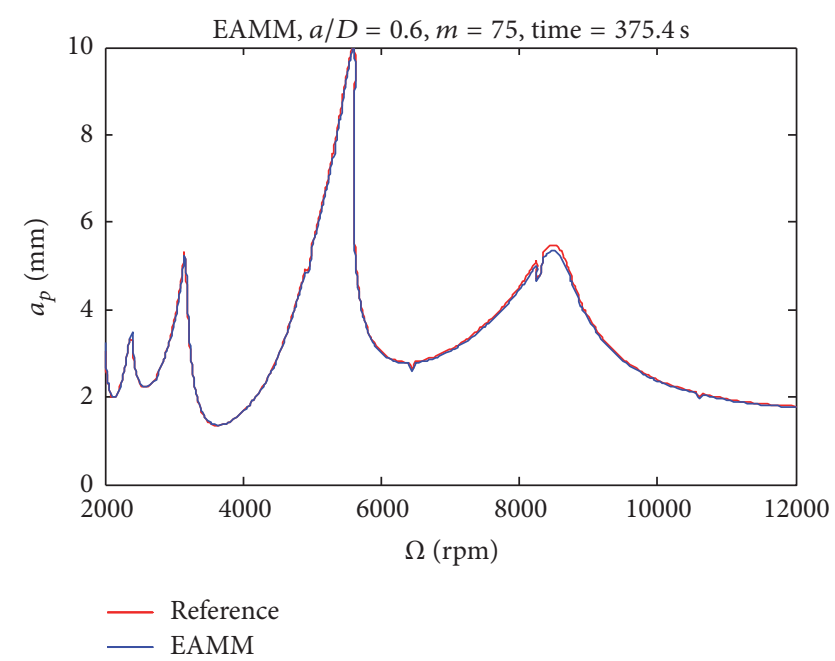

(f)

FIgURE 2: Stability lobe diagrams computed by the SDM, the EMHPM, and the EAMM with the radial immersion ratio $a / D=0.6$. 


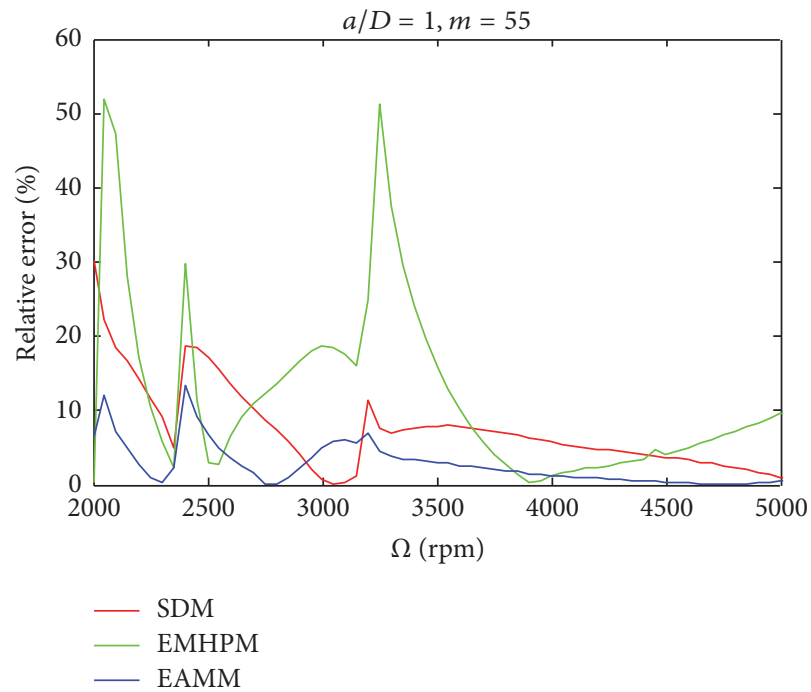

(a)

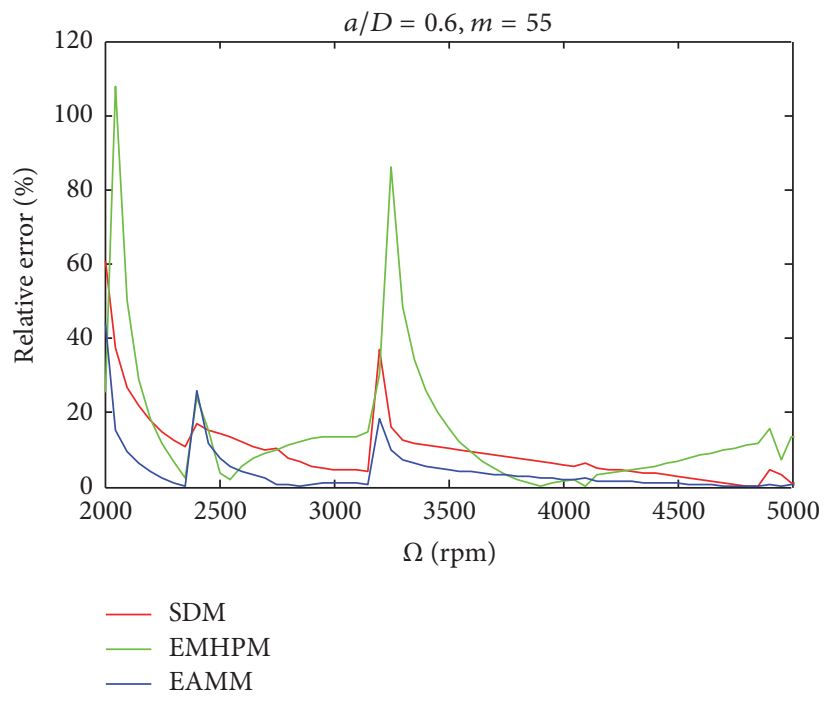

(c)

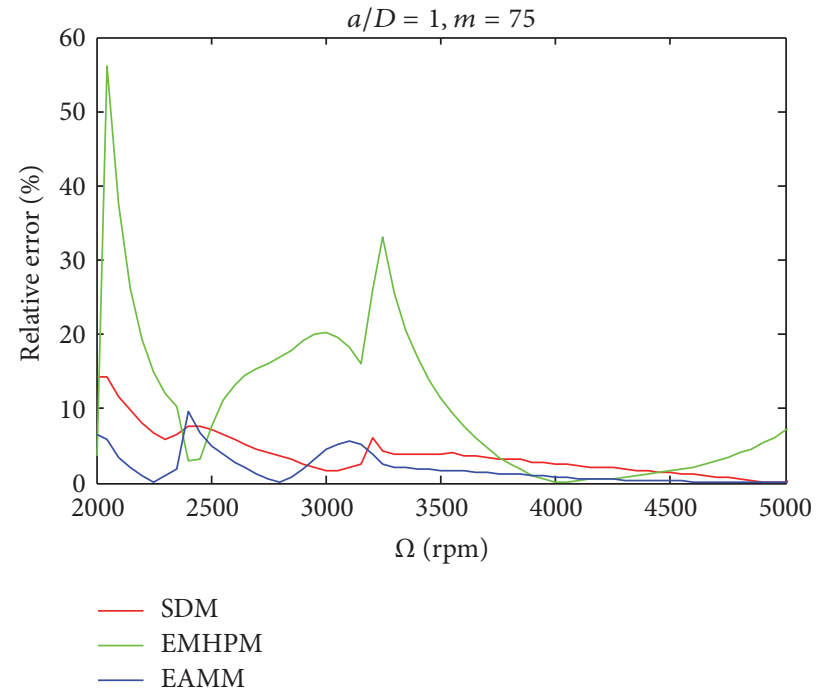

(b)

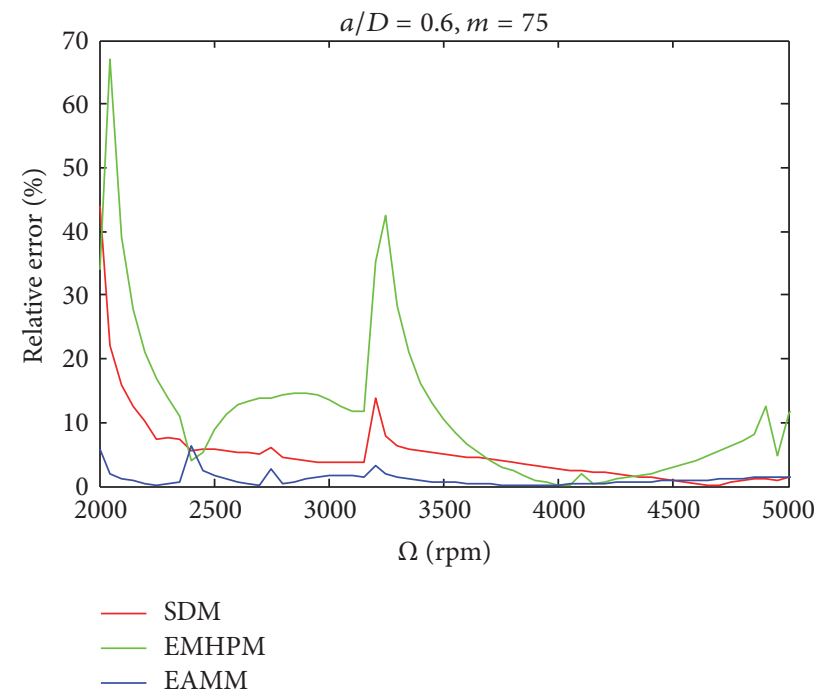

(d)

FIGURE 3: Comparisons of relative errors among the SDM, the EMHPM, and the EAMM with the radial immersion ratio $a / D=1$ and $a / D=0.6$.

\section{Conclusion}

In this work, an efficient and accurate semianalytical algorithm is proposed for the stability prediction of milling processes with multiple delays. Firstly, the milling dynamics model for regenerative chatter is rewritten in the state-space form. After the spindle rotation period is equally discretized, the delay terms are approximated by Lagrange interpolation polynomials, and the Adams-Moulton method is employed to construct the Floquet transition matrix. Finally, the stability of milling operations can be predicted by examining the spectral radius of the Floquet transition matrix. A twoDOF milling model with variable pitch tool has been adopted to demonstrate the proposed method. The numerical results demonstrate that under the same computational condition the proposed method achieves a higher computational efficiency than the SDM and the EMHPM. Compared with the SDM and the EMHPM, the computation time of the proposed method can be reduced by $67-70 \%$ and $45-53 \%$, respectively. In general, the accuracy of the EAMM is higher than the SDM and the EMHPM. In addition, the accuracy of the stability lobe diagrams computed by the proposed method can be improved significantly over the spindle speed range from $2000 \mathrm{rpm}$ to $5000 \mathrm{rpm}$.

\section{Conflicts of Interest}

The authors declare that they have no conflicts of interest. 

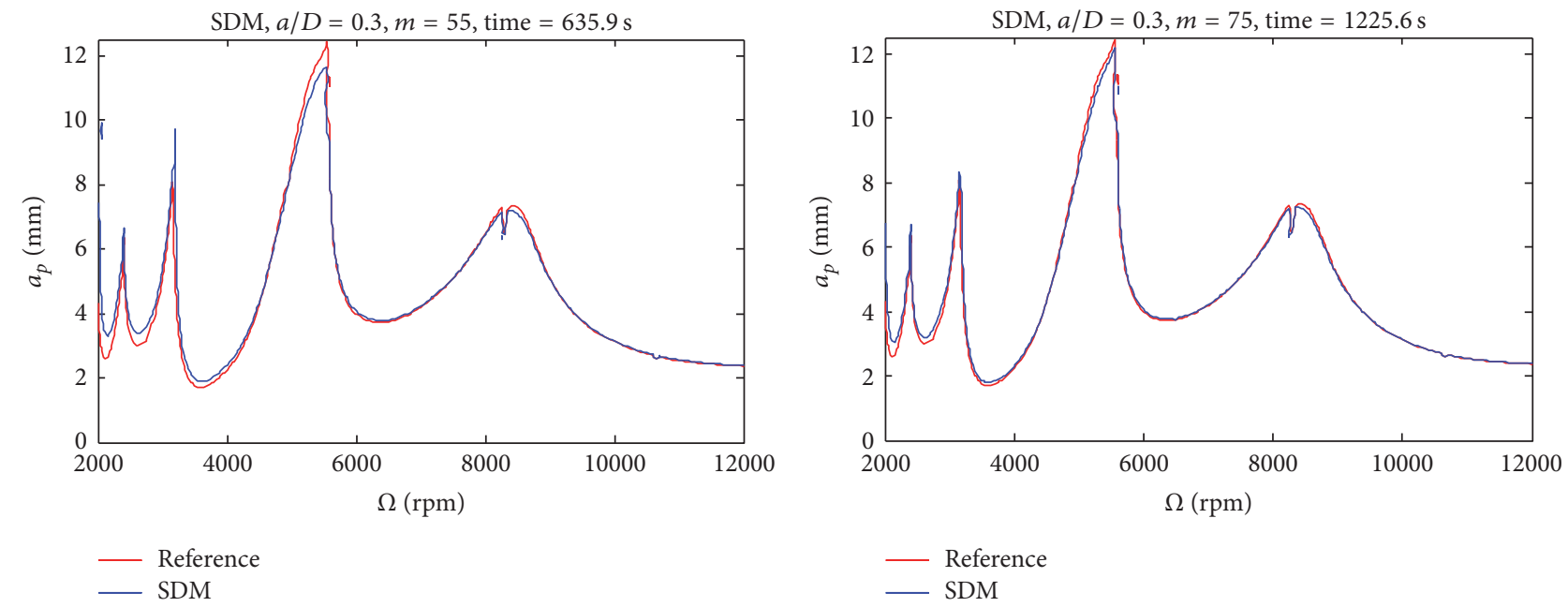

(a)

(b)
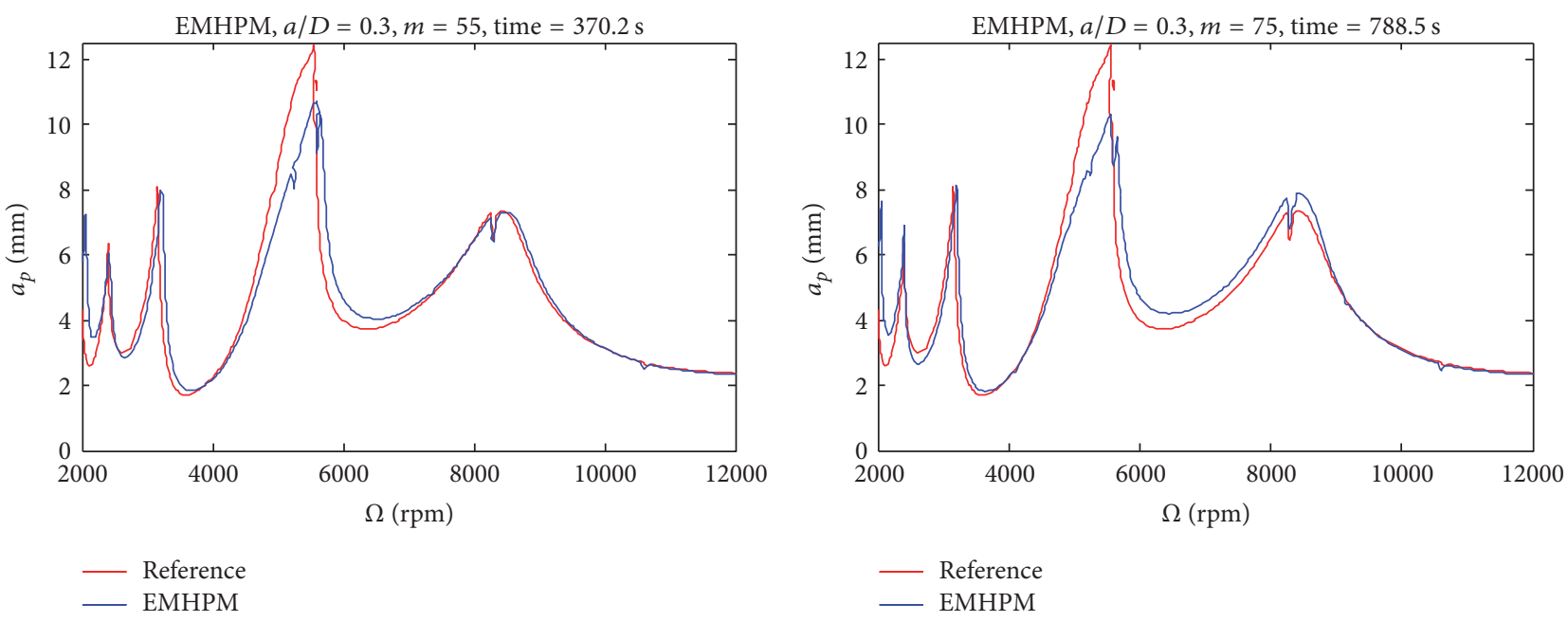

(c)

(d)

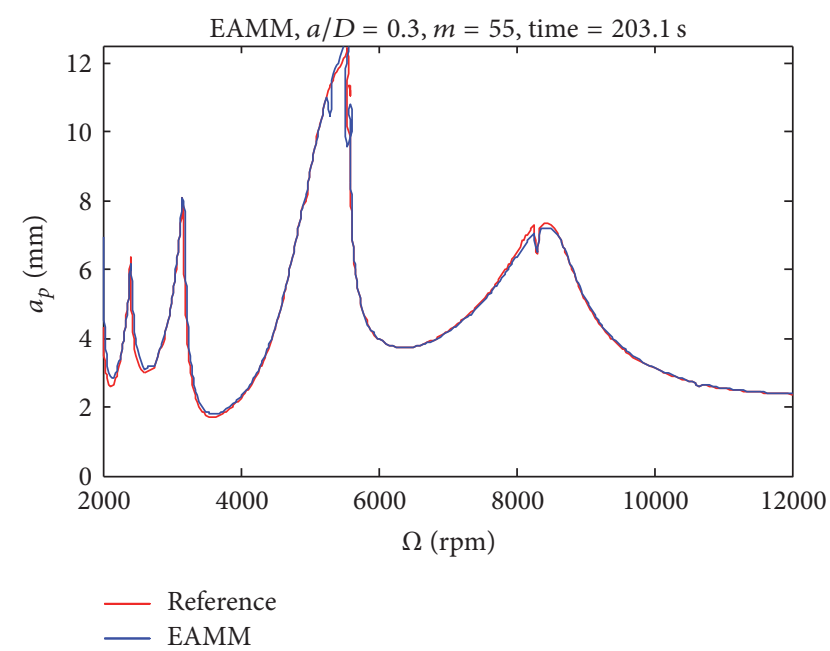

(e)

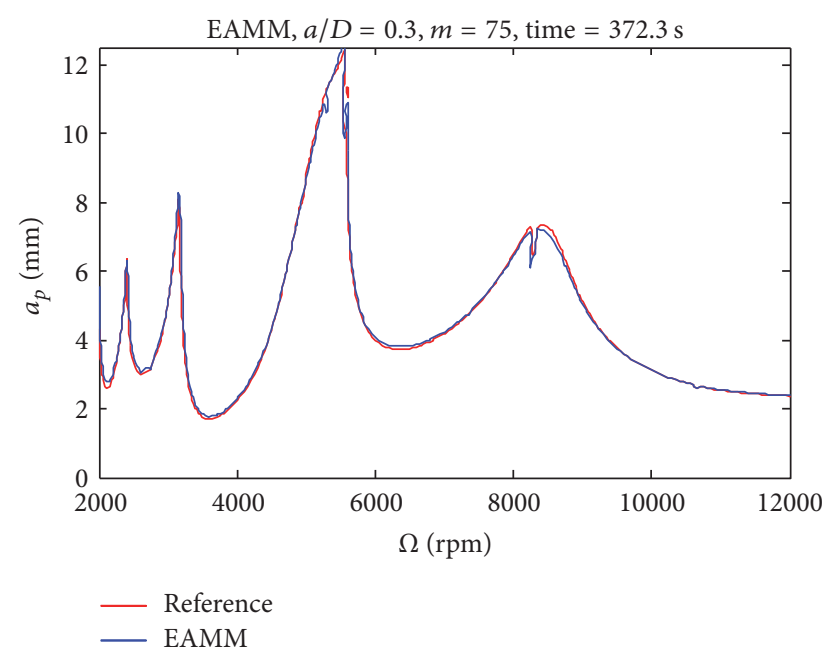

(f)

FIGURE 4: Stability lobe diagrams computed by the SDM, the EMHPM, and the EAMM with the radial immersion ratio $a / D=0.3$. 

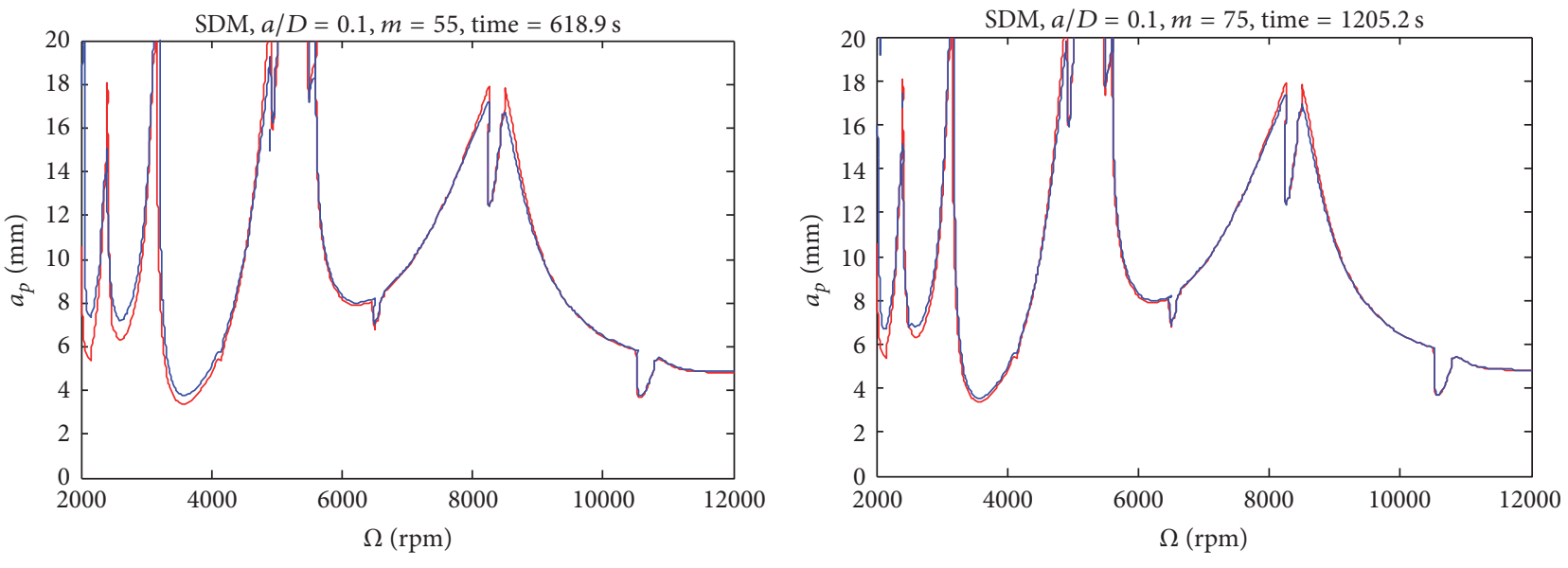

- Reference

- Reference

(a)
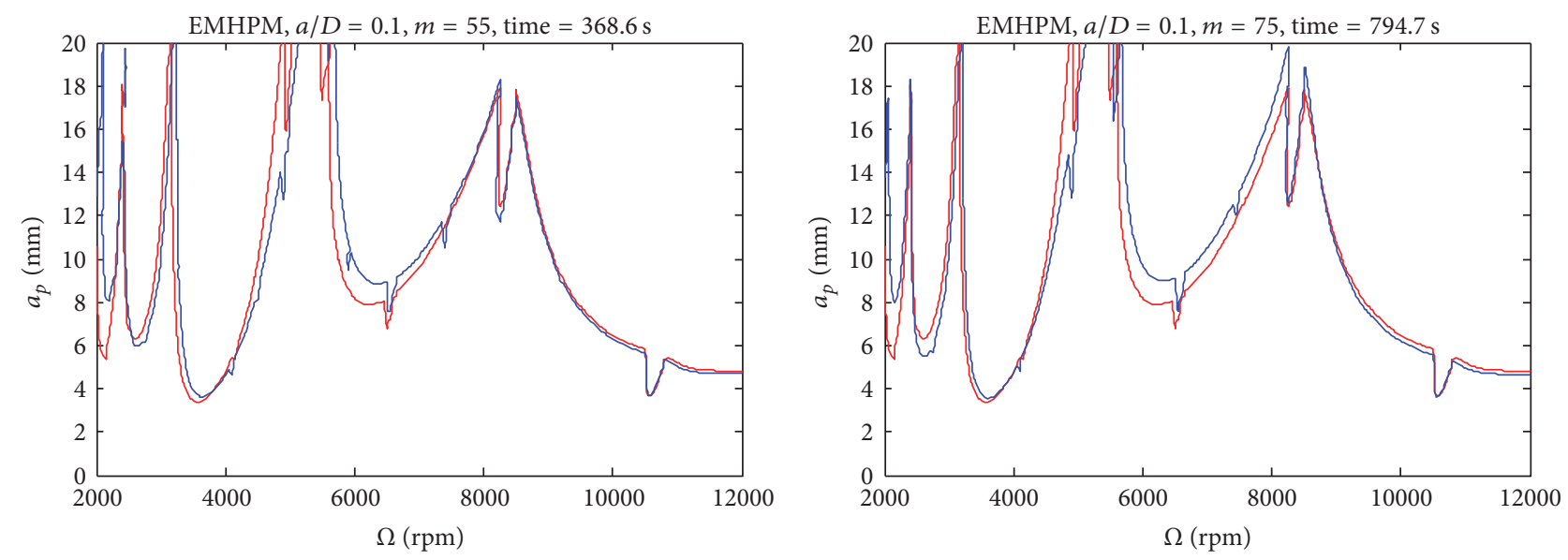

- Reference

— EMHPM

- Reference

— EMHPM

(c)

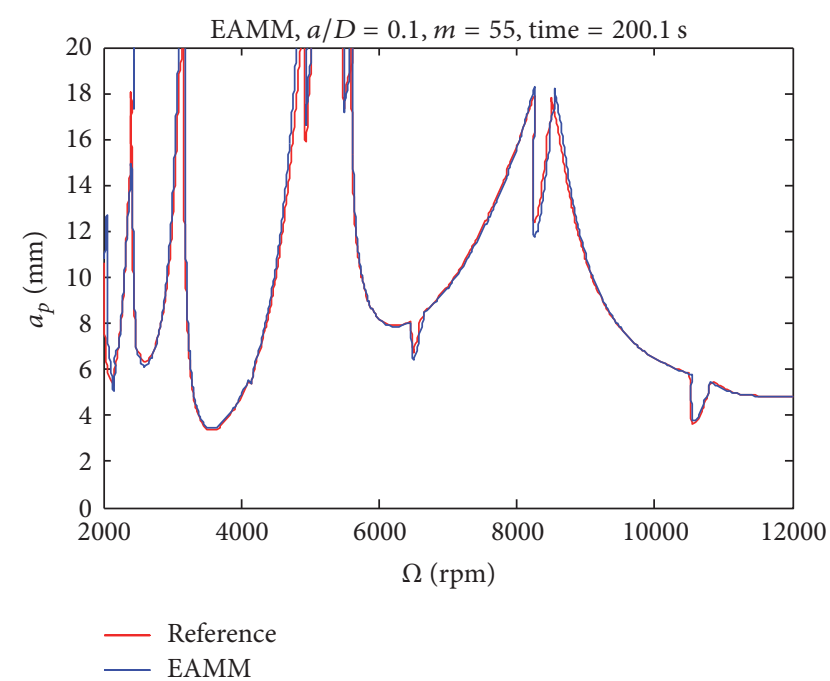

(e)

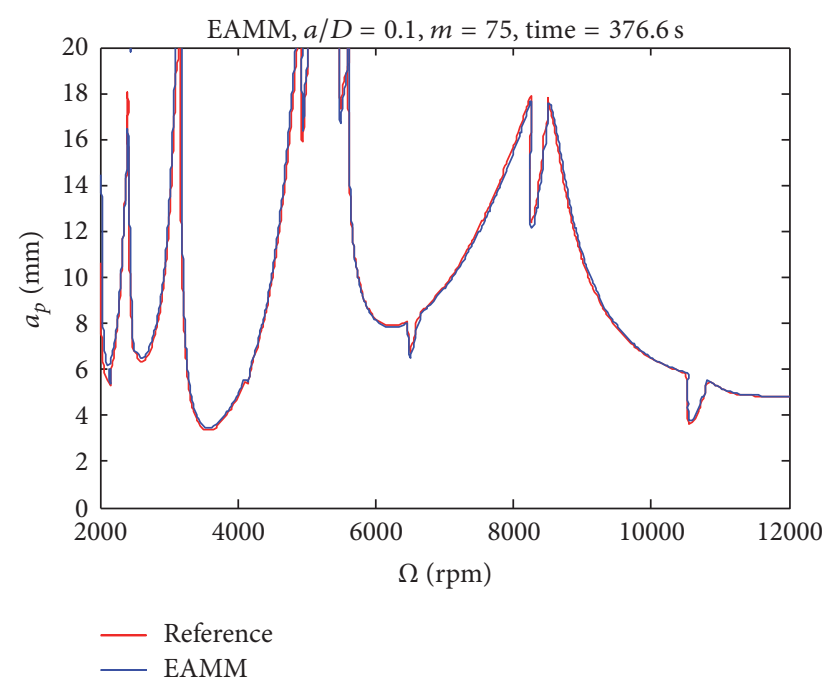

(f)

FIGURE 5: Stability lobe diagrams computed by the SDM, the EMHPM, and the EAMM with the radial immersion ratio $a / D=0.1$. 


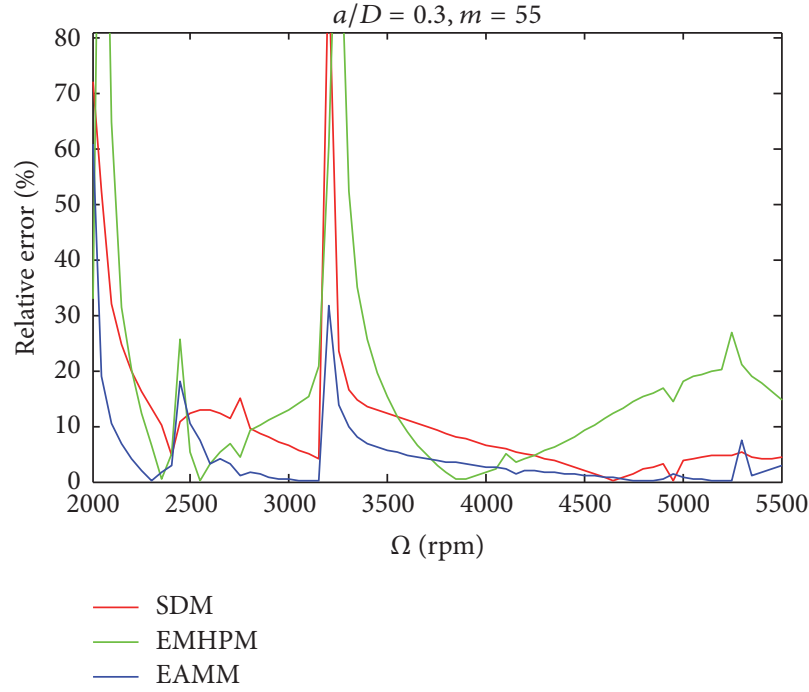

(a)

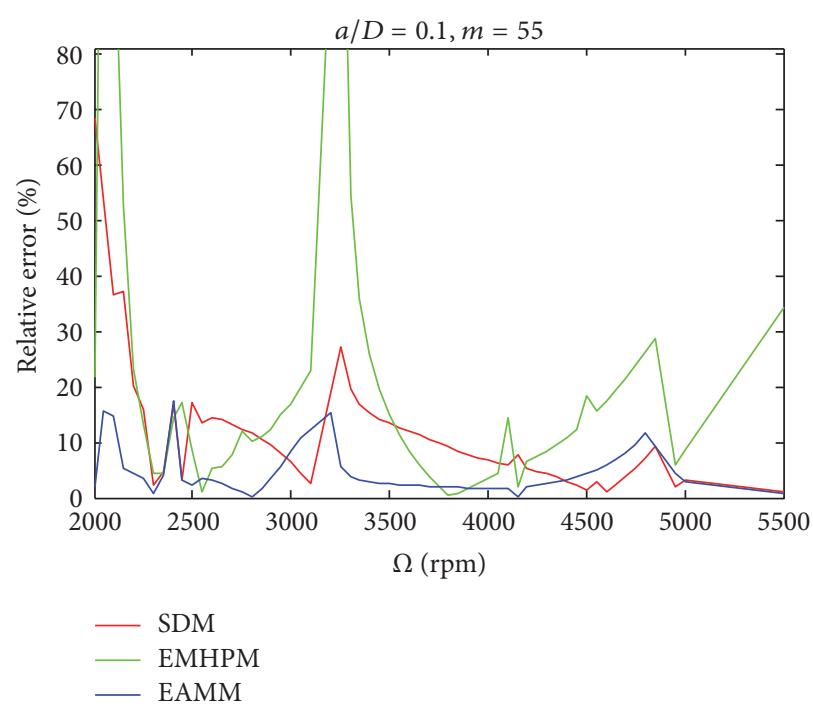

(c)

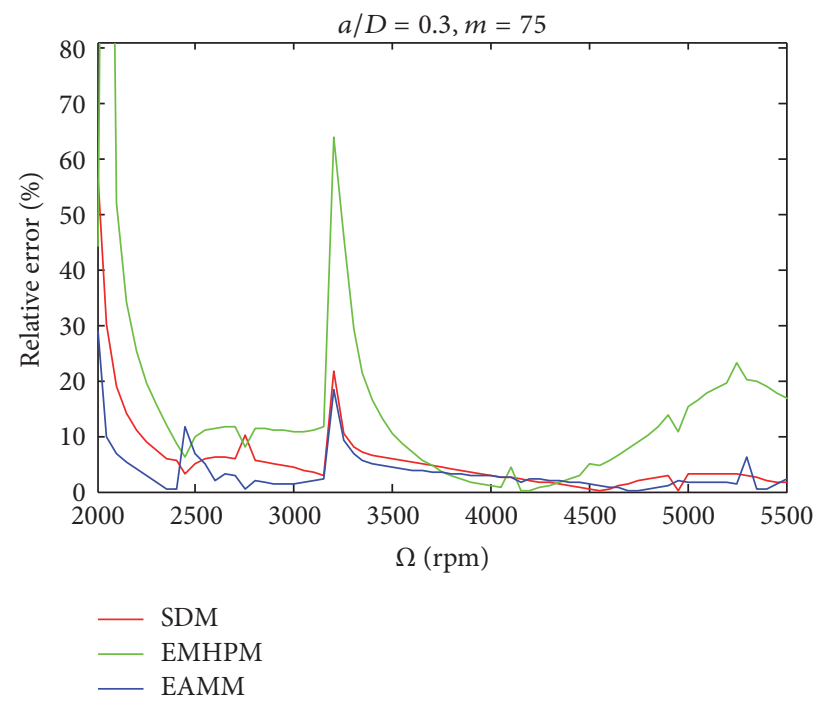

(b)

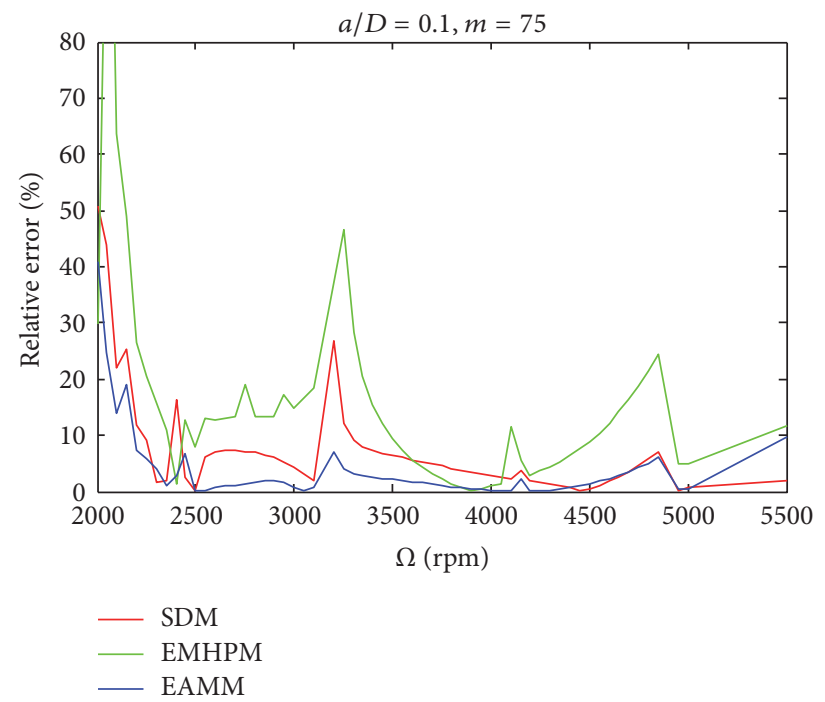

(d)

FIGURE 6: Comparisons of relative errors among the SDM, the EMHPM, and the EAMM with the radial immersion ratio $a / D=0.3$ and $a / D=0.1$.

\section{Acknowledgments}

This work was partially supported by the Innovation Fund of National Business Aircraft Manufacturing Engineering Technology Research Center (Grant no. SAMC14-JS-15-046), the National Natural Science Foundation of China (NSFC) (Grant no. 51375297), and the Program of Shanghai Subject Chief Scientist (Grant no. 14XD1402000).

\section{References}

[1] Y. Altıntaş, G. Stepan, D. Merdol, and Z. Dombovari, "Chatter stability of milling in frequency and discrete time domain," CIRP Journal of Manufacturing Science and Technology, vol. 1, no. 1, pp. 35-44, 2008.
[2] H. Ding, Y. Ding, and L. Zhu, "On time-domain methods for milling stability analysis," Chinese Science Bulletin, vol. 57, no. 33, pp. 4336-4345, 2012.

[3] J. Munoa, X. Beudaert, Z. Dombovari et al., "Chatter suppression techniques in metal cutting," CIRP Annals_Manufacturing Technology, vol. 65, no. 2, pp. 785-808, 2016.

[4] M. Wiercigroch and E. Budak, "Sources of nonlinearities, chatter generation and suppression in metal cutting," Philosophical Transactions of the Royal Society A: Mathematical, Physical and Engineering Sciences, vol. 359, no. 1781, pp. 663-693, 2001.

[5] Y. Altıntaş and M. Weck, "Chatter stability of metal cutting and grinding," CIRP Annals-Manufacturing Technology, vol. 53, no. 2, pp. 619-642, 2004.

[6] T. Insperger and G. Stepan, Semi-Discretization for Time-Delay Systems: Stability and Engineering Applications, vol. 178 of 
Applied Mathematical Sciences, Springer, New York, NY, USA, 2011.

[7] M. A. Davies, J. R. Pratt, B. S. Dutterer, and T. J. Burns, "Stability of low radial immersion milling," CIRP Annals-Manufacturing Technology, vol. 49, no. 1, pp. 37-40, 2000.

[8] M. L. Campomanes and Y. Altıntaş, "An improved time domain simulation for dynamic milling at small radial immersions," Journal of Manufacturing Science and Engineering, Transactions of the ASME, vol. 125, no. 3, pp. 416-422, 2003.

[9] Z. Li and Q. Liu, "Solution and analysis of chatter stability for end milling in the time-domain," Chinese Journal of Aeronautics, vol. 21, no. 2, pp. 169-178, 2008.

[10] G. Urbikain, D. Olvera, and L. N. L. de Lacalle, "Stability contour maps with barrel cutters considering the tool orientation," The International Journal of Advanced Manufacturing Technology, vol. 89, no. 9, pp. 2491-2501, 2017.

[11] Y. Altıntaş and E. Budak, "Analytical prediction of stability lobes in milling," CIRP Annals-Manufacturing Technology, vol. 44, no. 1, pp. 357-362, 1995.

[12] E. Budak and Y. Altıntaş, "Analytical prediction of chatter stability in milling - part II: application of the general formulation to common milling systems," Journal of Dynamic Systems, Measurement and Control, Transactions of the ASME, vol. 120, no. 1, pp. 31-36, 1998.

[13] S. D. Merdol and Y. Altıntaş, "Multi frequency solution of chatter stability for low immersion milling," Journal of Manufacturing Science and Engineering, Transactions of the ASME, vol. 126, no. 3, pp. 459-466, 2004.

[14] P. V. Bayly, B. P. Mann, T. L. Schmitz, D. A. Peters, G. Stepan, and T. Insperger, "Effects of radial immersion and cutting direction on chatter instability in end-milling," in Proceedings of ASME International Mechanical Engineering Congress and Exposition, Paper No. IMECE2002-39116, pp. 351-363, New Orleans, Louisiana, La, USA, November, 2002.

[15] E. A. Butcher, O. A. Bobrenkov, E. Bueler, and P. Nindujarla, "Analysis of milling stability by the chebyshev collocation method: algorithm and optimal stable immersion levels," Journal of Computational and Nonlinear Dynamics, vol. 4, no. 3, Article ID 031003, 12 pages, 2009.

[16] G. Urbikain, L. N. López de Lacalle, F. J. Campa, A. Fernández, and A. Elías, "Stability prediction in straight turning of a flexible workpiece by collocation method," International Journal of Machine Tools and Manufacture, vol. 54-55, pp. 73-81, 2012.

[17] G. Urbikain, A. Fernández, L. N. López de Lacalle, and M. E. Gutiérrez, "Stability lobes for general turning operations with slender tools in the tangential direction," International Journal of Machine Tools and Manufacture, vol. 67, pp. 35-44, 2013.

[18] G. Urbikain, F.-J. Campa, J.-J. Zulaika, L.-N. López De Lacalle, M.-A. Alonso, and V. Collado, "Preventing chatter vibrations in heavy-duty turning operations in large horizontal lathes," Journal of Sound and Vibration, vol. 340, pp. 317-330, 2015.

[19] G. Urbikain, D. Olvera, L. N. L. de Lacalle, and A. Elías-Zúñiga, "Stability and vibrational behaviour in turning processes with low rotational speeds," International Journal of Advanced Manufacturing Technology, vol. 80, no. 5-8, pp. 871-885, 2015.

[20] T. Insperger and G. Stépán, "Semi-discretization method for delayed systems," International Journal for Numerical Methods in Engineering, vol. 55, no. 5, pp. 503-518, 2002.

[21] T. Insperger and G. Stépán, "Updated semi-discretization method for periodic delay-differential equations with discrete delay," International Journal for Numerical Methods in Engineering, vol. 61, no. 1, pp. 117-141, 2004.
[22] T. Insperger, G. Stépán, and J. Turi, "On the higher-order semidiscretizations for periodic delayed systems," Journal of Sound and Vibration, vol. 313, no. 1-2, pp. 334-341, 2008.

[23] S. L. Jiang, Y. W. Sun, X. L. Yuan, and W. R. Liu, "A secondorder semi-discretization method for the efficient and accurate stability prediction of milling process," The International Journal of Advanced Manufacturing Technology, 2017.

[24] Y. Ding, L. Zhu, X. Zhang, and H. Ding, "A full-discretization method for prediction of milling stability," International Journal of Machine Tools and Manufacture, vol. 50, no. 5, pp. 502-509, 2010.

[25] Y. Ding, L. Zhu, X. Zhang, and H. Ding, "Second-order fulldiscretization method for milling stability prediction," International Journal of Machine Tools and Manufacture, vol. 50, no. 10, pp. 926-932, 2010.

[26] Q. Quo, Y. Sun, and Y. Jiang, "On the accurate calculation of milling stability limits using third-order full-discretization method," International Journal of Machine Tools and Manufacture, vol. 62, pp. 61-66, 2012.

[27] C. G. Ozoegwu, S. N. Omenyi, and S. M. Ofochebe, "Hyperthird order full-discretization methods in milling stability prediction," International Journal of Machine Tools and Manufacture, vol. 92, pp. 1-9, 2015.

[28] Y. Ding, L. Zhu, X. Zhang, and H. Ding, "Numerical integration method for prediction of milling stability," Journal of Manufacturing Science and Engineering, Transactions of the ASME, vol. 133, no. 3, Article ID 031005, 9 pages, 2011.

[29] Y. Ding, J. Niu, L. Zhu, and H. Ding, "Numerical integration method for stability analysis of milling with variable spindle speeds," Journal of Vibration and Acoustics, Transactions of the ASME, vol. 138, no. 1, Article ID 011010, 11 pages, 2016.

[30] J. Niu, Y. Ding, L. Zhu, and H. Ding, "Stability Analysis of Milling Processes with Periodic Spindle Speed Variation Via the Variable-Step Numerical Integration Method," Journal of Manufacturing Science and Engineering, Transactions of the ASME, vol. 138, no. 11, Article ID 114501, 11 pages, 2016.

[31] M. Li, G. Zhang, and Y. Huang, "Complete discretization scheme for milling stability prediction," Nonlinear Dynamics, vol. 71, no. 1-2, pp. 187-199, 2013.

[32] Q. Xie, "Milling stability prediction using an improved complete discretization method," International Journal of Advanced Manufacturing Technology, vol. 83, no. 5-8, pp. 815-821, 2016.

[33] Z. Li, Z. Yang, Y. Peng, F. Zhu, and X. Ming, "Prediction of chatter stability for milling process using Runge-Kuttabased complete discretization method," International Journal of Advanced Manufacturing Technology, vol. 86, no. 1-4, pp. 943952, 2016.

[34] Y. Ding, L. M. Zhu, X. J. Zhang, and H. Ding, "Stability analysis of milling via the differential quadrature method," Journal of Manufacturing Science and Engineering, Transactions of the ASME, vol. 135, no. 4, Article ID 044502, 7 pages, 2013.

[35] D. Olvera, A. Elías-Zúñiga, H. Martínez-Alfaro, L. N. López De Lacalle, C. A. Rodríguez, and F. J. Campa, "Determination of the stability lobes in milling operations based on homotopy and simulated annealing techniques," Mechatronics, vol. 24, no. 3, pp. 177-185, 2014.

[36] J. Niu, Y. Ding, L. Zhu, and H. Ding, "Runge-Kutta methods for a semi-analytical prediction of milling stability," Nonlinear Dynamics, vol. 76, no. 1, pp. 289-304, 2014.

[37] Y. Ding, L. Zhu, and H. Ding, "A wavelet-based approach for stability analysis of periodic delay-differential systems with 
discrete delay," Nonlinear Dynamics, vol. 79, no. 2, pp. 10491059, 2015.

[38] Z. Zhang, H. G. Li, G. Meng, and C. Liu, "A novel approach for the prediction of the milling stability based on the Simpson method," International Journal of Machine Tools and Manufacture, vol. 99, pp. 43-47, 2015.

[39] X. Zhang, C. Xiong, Y. Ding, and H. Ding, "Prediction of chatter stability in high speed milling using the numerical differentiation method," International Journal of Advanced Manufacturing Technology, vol. 89, no. 9, pp. 2535-2544, 2017.

[40] C. Qin, J. Tao, L. Li, and C. Liu, "An Adams-Moulton-based method for stability prediction of milling processes," International Journal of Advanced Manufacturing Technology, vol. 89, no. 9, pp. 3049-3058, 2017.

[41] Y. Altıntaş, S. Engin, and E. Budak, "Analytical stability prediction and design of variable pitch cutters," Journal of Manufacturing Science and Engineering, Transactions of the ASME, vol. 121, no. 2, pp. 173-178, 1999.

[42] E. Budak, "An analytical design method for milling cutters with nonconstant pitch to increase stability, part I: theory," Journal of Manufacturing Science and Engineering, Transactions of the ASME, vol. 125, no. 1, pp. 29-34, 2003.

[43] E. Budak, "An analytical design method for milling cutters with nonconstant pitch to increase stability, part 2: application," Journal of Manufacturing Science and Engineering, Transactions of the ASME, vol. 125, no. 1, pp. 35-38, 2003.

[44] N. Olgac and R. Sipahi, "Dynamics and stability of variablepitch milling," JVC/Journal of Vibration and Control, vol. 13, no. 7, pp. 1031-1043, 2007.

[45] N. D. Sims, B. Mann, and S. Huyanan, "Analytical prediction of chatter stability for variable pitch and variable helix milling tools," Journal of Sound and Vibration, vol. 317, no. 3-5, pp. 664686, 2008.

[46] M. Wan, W.-H. Zhang, J.-W. Dang, and Y. Yang, "A unified stability prediction method for milling process with multiple delays," International Journal of Machine Tools and Manufacture, vol. 50, no. 1, pp. 29-41, 2010.

[47] X. Zhang, C. H. Xiong, and Y. Ding, "Improved fulldiscretization method for milling chatter stability prediction with multiple delays," in Intelligent Robotics and Applications, vol. 6425, pp. 541-552, Springer, Heidelberg, Germany, 2010.

[48] X. Zhang, C. Xiong, Y. Ding, and Y. Xiong, "Variable-step integration method for milling chatter stability prediction with multiple delays," Science China Technological Sciences, vol. 54, no. 12, pp. 3137-3154, 2011.

[49] F. I. Compeán, D. Olvera, F. J. Campa, L. N. López De Lacalle, A. Elías-Zúñiga, and C. A. Rodríguez, "Characterization and stability analysis of a multivariable milling tool by the enhanced multistage homotopy perturbation method," International Journal of Machine Tools and Manufacture, vol. 57, pp. 27-33, 2012.

[50] F. A. Khasawneh and B. P. Mann, "A spectral element approach for the stability analysis of time-periodic delay equations with multiple delays," Communications in Nonlinear Science and Numerical Simulation, vol. 18, no. 8, pp. 2129-2141, 2013.

[51] G. Jin, Q. Zhang, S. Hao, and Q. Xie, "Stability prediction of milling process with variable pitch cutter," Mathematical Problems in Engineering, vol. 2013, Article ID 932013, 11 pages, 2013.

[52] G. Jin, Q. Zhang, S. Hao, and Q. Xie, "Stability prediction of milling process with variable pitch and variable helix cutters," Proceedings of the Institution of Mechanical Engineers, Part C:
Journal of Mechanical Engineering Science, vol. 228, no. 2, pp. 281-293, 2014.

[53] G. Jin, H. Qi, Y. Cai, and Q. Zhang, "Stability prediction for milling process with multiple delays using an improved semidiscretization method," Mathematical Methods in the Applied Sciences, vol. 39, no. 4, pp. 949-958, 2016.

[54] N. D. Sims, "Fast chatter stability prediction for variable helix milling tools," Proceedings of the Institution of Mechanical Engineers, Part C: Journal of Mechanical Engineering Science, vol. 230, no. 1, pp. 133-144, 2016.

[55] Y. Ding, J. B. Niu, L. M. Zhu, and H. Ding, "Differential quadrature method for stability analysis of dynamic systems with multiple delays: application to simultaneous machining operations," Journal of Vibration and Acoustics, Transactions of the ASME, vol. 137, no. 2, Article ID 024501, 8 pages, 2015.

[56] Q. Guo, Y. Jiang, B. Zhao, and P. Ming, "Chatter modeling and stability lobes predicting for non-uniform helix tools," International Journal of Advanced Manufacturing Technology, vol. 87, no. 1, pp. 251-266, 2016. 


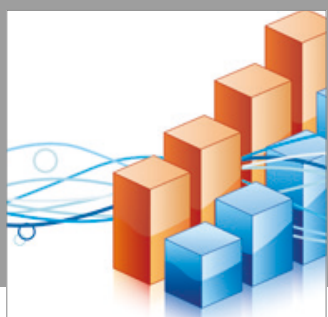

Advances in

Operations Research

vatersals

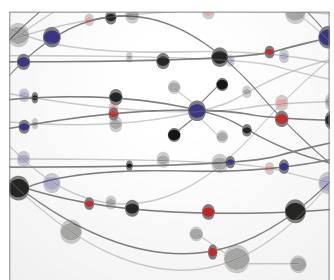

\section{The Scientific} World Journal
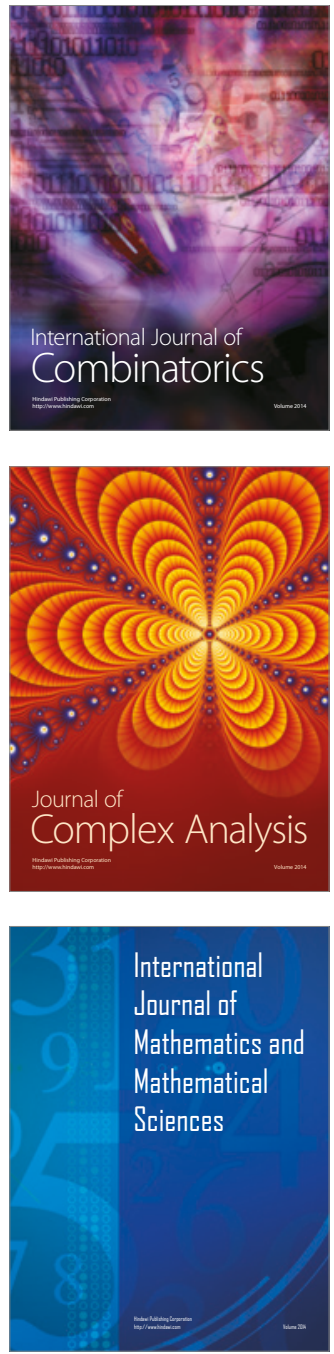
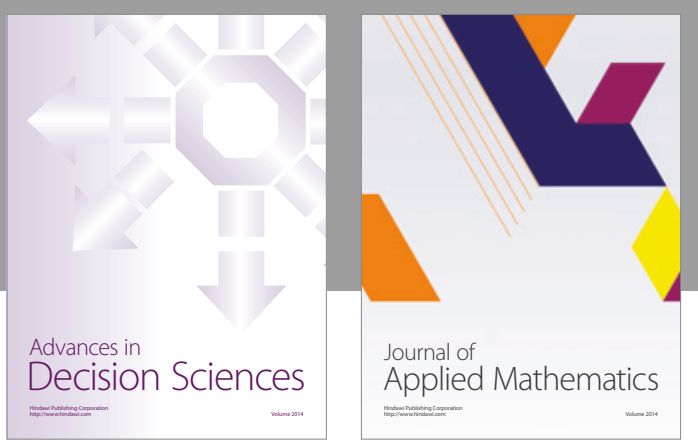

Algebra

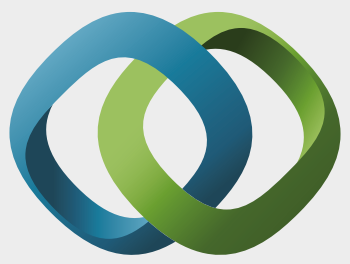

\section{Hindawi}

Submit your manuscripts at

https://www.hindawi.com
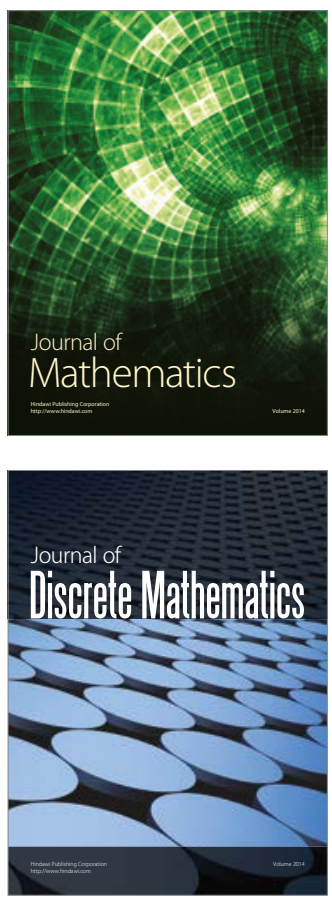

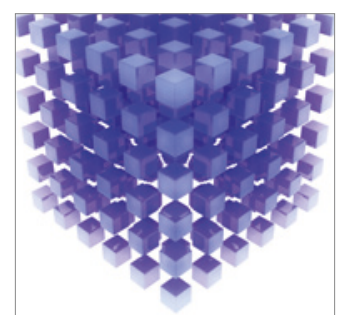

Mathematical Problems in Engineering
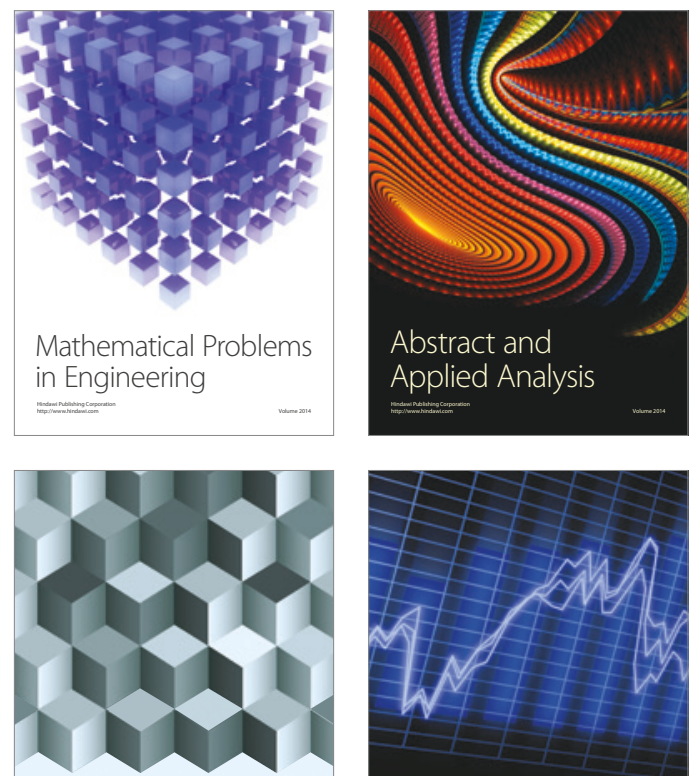

Journal of

Function Spaces

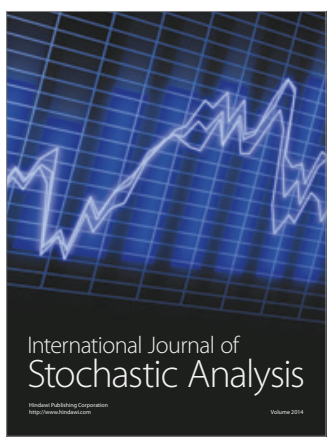

Probability and Statistics
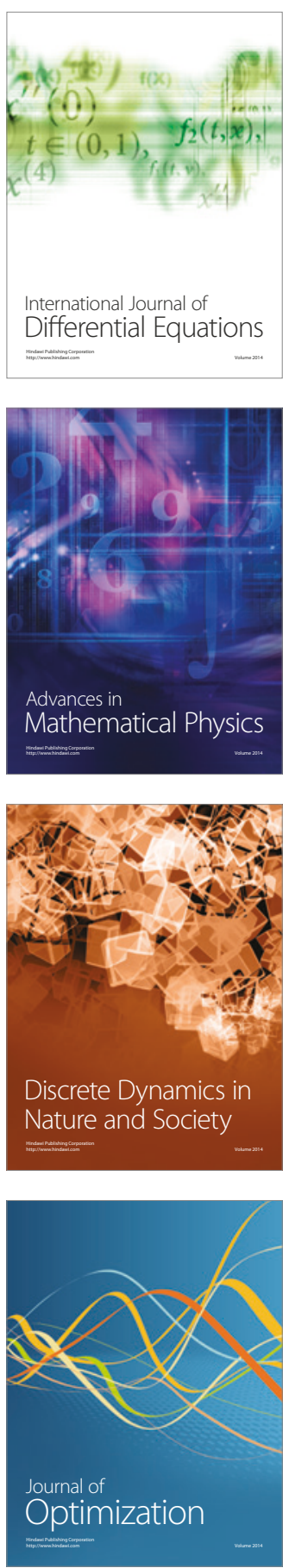